\title{
Risk scores for predicting early antiretroviral therapy mortality in sub-Saharan Africa to inform who needs intensification of care: a derivation and external validation cohort study
}

Andrew F. Auld ${ }^{1 *}$ (D) Katherine Fielding ${ }^{2,3}$, Tefera Agizew ${ }^{4}$, Alice Maida ${ }^{1}$, Anikie Mathoma ${ }^{4}$, Rosanna Boyd ${ }^{4}$, Anand Date ${ }^{5}$, Sherri L. Pals ${ }^{5}$, George Bicego ${ }^{5}$, Yuliang Liu', Ray W. Shiraishi ${ }^{5}$, Peter Ehrenkranz ${ }^{6}$, Christopher Serumola ${ }^{4}$, Unami Mathebula ${ }^{4}$, Heather Alexander ${ }^{5}$, Salome Charalambous ${ }^{7}$, Courtney Emerson ${ }^{5}$, Goabaone Rankgoane-Pono ${ }^{8}$, Pontsho Pono ${ }^{8}$, Alyssa Finlay ${ }^{4}$, James C. Shepherd ${ }^{4,9}$, Charles Holmes ${ }^{10}$, Tedd V. Ellerbrock ${ }^{5}$ and Alison D. Grant ${ }^{2,3,11}$

\footnotetext{
Abstract

Background: Clinical scores to determine early (6-month) antiretroviral therapy (ART) mortality risk have not been developed for sub-Saharan Africa (SSA), home to $70 \%$ of people living with HIV. In the absence of validated scores, WHO eligibility criteria (EC) for ART care intensification are CD4<200/uL or WHO stage III/IV.

Methods: We used Botswana XPRES trial data for adult ART enrollees to develop CD4-independent and CD4dependent multivariable prognostic models for 6-month mortality. Scores were derived by rescaling coefficients. Scores were developed using the first $50 \%$ of XPRES ART enrollees, and their accuracy validated internally and externally using South African TB Fast Track (TBFT) trial data. Predictive accuracy was compared between scores and WHO EC.

\footnotetext{
* Correspondence: aauld@cdc.gov

'Division of Global HIV \& TB, United States Centers for Disease Control and Prevention (CDC), Nico House, City Centre, P.O. Box 30016, Lilongwe 3,

Malawi

Full list of author information is available at the end of the article
}

(c) The Author(s). 2020 Open Access This article is licensed under a Creative Commons Attribution 4.0 International License, which permits use, sharing, adaptation, distribution and reproduction in any medium or format, as long as you give appropriate credit to the original author(s) and the source, provide a link to the Creative Commons licence, and indicate if changes were made. The images or other third party material in this article are included in the article's Creative Commons licence, unless indicated otherwise in a credit line to the material. If material is not included in the article's Creative Commons licence and your intended use is not permitted by statutory regulation or exceeds the permitted use, you will need to obtain permission directly from the copyright holder. To view a copy of this licence, visit http://creativecommons.org/licenses/by/4.0/ The Creative Commons Public Domain Dedication waiver (http://creativecommons.org/publicdomain/zero/1.0/) applies to the data made available in this article, unless otherwise stated in a credit line to the data. 
(Continued from previous page)

Results: Among 5553 XPRES enrollees, 2838 were included in the derivation dataset; 68\% were female and 83 (3\%) died by 6 months. Among 1077 TBFT ART enrollees, 55\% were female and 6\% died by 6 months. Factors predictive of 6-month mortality in the derivation dataset at $p<0.01$ and selected for the CD4-independent score included male gender (2 points), $\geq 1$ WHO tuberculosis symptom (2 points), WHO stage III/IV (2 points), severe anemia (hemoglobin $<8 \mathrm{~g} / \mathrm{dL}$ ) (3 points), and temperature $>37.5^{\circ} \mathrm{C}$ (2 points). The same variables plus CD $4<200 / \mu \mathrm{L}(1$ point) were included in the CD4-dependent score. Among XPRES enrollees, a CD4-independent score of $\geq 4$ would provide $86 \%$ sensitivity and $66 \%$ specificity, whereas WHO EC would provide $83 \%$ sensitivity and 58\% specificity. If WHO stage alone was used, sensitivity was 48\% and specificity 89\%. Among TBFT enrollees, the CD4-independent score of $\geq 4$ would provide $95 \%$ sensitivity and 27\% specificity, whereas WHO EC would provide 100\% sensitivity but $0 \%$ specificity. Accuracy was similar between CD4-independent and CD4-dependent scores. Categorizing CD4independent scores into low (<4), moderate (4-6), and high risk ( $\geq 7$ ) gave 6-month mortality of 1\%, 4\%, and 17\% for XPRES and 1\%, 5\%, and 30\% for TBFT enrollees.

Conclusions: Sensitivity of the CD4-independent score was nearly twice that of WHO stage in predicting 6-month mortality and could be used in settings lacking CD4 testing to inform ART care intensification. The CD4-dependent score improved specificity versus WHO EC. Both scores should be considered for scale-up in SSA.

Keywords: HIV, Acquired immuno-deficiency syndrome, Antiretroviral therapy, Mortality, Predictive models, Clinical scores

\section{Background}

Over the last 16 years, the scale-up of HIV treatment globally has reached over 24.5 million people living with HIV (PLHIV) with lifesaving antiretroviral therapy (ART), resulting in declines in both HIV-associated mortality and HIV incidence [1-3]. However, each year there are still about 770,000 global AIDS-related deaths, with $470,000(61 \%)$ of these deaths occurring in sub-Saharan Africa (SSA) [1]. To reduce AIDS-related mortality, the global community is striving to reach 2030 targets of ensuring at least $90 \%$ of PLHIV are on ART [4], which will require ART enrollment for an additional 10 million of the 37.9 million PLHIV globally, about two-thirds of whom live in sub-Saharan Africa (SSA) [1]. Mortality rates during ART are highest in the first 6 months of therapy, and these early ART mortality rates continue to be highest in SSA [5, 6]. If 2030 goals of reducing AIDSrelated mortality by $90 \%$ compared with 2010 are to be met, substantial progress needs to be made in addressing early ART mortality in SSA [5, 6], where 20-40\% of new ART enrollees still initiate ART with relatively advanced HIV disease [7, 8].

To achieve these mortality reductions, efficient use of available resources through differentiated service delivery (DSD) models to provide tailored, patient-centered care will be needed $[9,10]$. The World Health Organization (WHO) currently recommends intensification of care for persons > 5 years old starting ART with advanced HIV disease as defined by CD4 ${ }^{+} \mathrm{T}$ cell (CD4) count $<200$ cells/ $\mu \mathrm{L}$ or WHO stage III/IV [8]. The intensification of care package, which has been shown to reduce early mortality [11], includes cotrimoxazole prophylaxis, tuberculosis (TB) screening with subsequent $\mathrm{TB}$ treatment or TB preventive therapy, cryptococcal antigen ( $\mathrm{CrAg}$ ) screening with pre-emptive therapy for eligible $\mathrm{CrAg}$-positive people, and enhanced adherence counseling. However, the majority of health facilities providing ART in low- and middle-income countries (LMIC) lack access to rapid or point-of-care (POC) CD4 testing [8]. In these settings, up to half of adults with a CD 4 count $<100 / \mu \mathrm{L}$ could be categorized as WHO stage I/II and would be missed by an advanced disease screening algorithm that relied on WHO stage alone [11]. In addition, a screening tool for advanced disease that relies only on CD4 count and WHO disease stage misses the many other demographic and clinical predictors associated with early ART mortality [9]. To date, most analyses evaluating eligibility for DSD models have focused on identifying stable patients for de-escalation of care [9]. Only one analysis from Haiti has evaluated a clinical score for determining who needs intensification of early ART care, and this was not externally validated [12].

Therefore, we evaluated whether a clinical score derived from easily available covariates at ART initiation in resource-constrained clinic settings could better predict who is at risk for early (6-month) ART mortality than the current WHO advanced disease eligibility criteria. We developed clinical scores to help predict early ART mortality risk for two scenarios: (1) a scenario where onsite/rapid off-site CD4 testing is not available as is the case for the majority of ART clinics in LMIC and (2) a scenario where on-site/rapid off-site CD4 testing is available.

\section{Methods}

We used data from the Xpert Package Rollout Evaluation using a Stepped-wedge design (XPRES) trial to 
derive the two clinical scores to help clinicians identify those at the highest risk of early ART mortality and therefore in need of ART care intensification [13]. The first clinical score assumes CD4 is unavailable at ART initiation (i.e., a CD4-independent score) and the second clinical score assumes CD4 count is available (i.e., a CD4-dependent score). We used the first $50 \%$ of XPRES cohort enrollees to derive a prediction model, and the second $50 \%$ to internally validate the model. We then used data from the TB Fast Track (TBFT) trial in South Africa (SA) to externally validate the derived clinical scores [14]. We compared the screening accuracy of our derived clinical scores with existing CD4-based WHO eligibility criteria for advanced disease and ART care intensification.

\section{XPRES study design and participants for prediction tool development}

XPRES was a multi-center, stepped-wedge cluster randomized trial with a retrospective baseline component conducted at 22 health facilities, including five hospitals and 17 clinics, that were purposively selected to be representative of HIV treatment clinics in Botswana [13]. In the prospective, stepped-wedge portion of the trial, all non-incarcerated, consenting, ART-naïve, HIV-positive persons, regardless of TB treatment or symptom status, presenting to the study clinics between August 2012 and end of March 2014, were eligible for enrollment. Only adolescents and adults (aged $\geq 12$ years old) were included in this analysis.

\section{XPRES procedures}

Per Botswana national guidelines during the time period of the study, all XPRES study participants were eligible for ART initiation if they had a CD4 count $\leq 350$ cells/ $\mu \mathrm{L}$, were diagnosed as having WHO stage III/IV events, or were pregnant or breastfeeding [15]. All study participants received clinical care and follow-up appointments per Ministry of Health $(\mathrm{MOH})$ guidelines (see Additional file 1 , a table summarizing standard clinical care follow-up).

\section{Interventions}

The prospective XPRES cohort was recruited within two phases of the stepped-wedge trial. In the first phase, all prospective XPRES participants received two enhanced care interventions in addition to standard of care: (1) additional support for intensified TB case finding and (2) intensified tracing for patients missing clinic appointments. In the second phase, the Xpert ${ }^{\circ}$ MTB/RIF assay (Cepheid; Sunnyvale, CA) (Xpert) was initiated in place of sputum smear microscopy for TB diagnosis. Details of these interventions have been previously published [16] and are provided in a supplementary appendix (see
Additional file 2, text describing enrollment and enhanced care interventions). We have previously shown that there was no significant difference in 6-month ART mortality between the two prospective phases of XPRES [16]. Enrollment and follow-up procedures are described in the supplementary appendix (see Additional file 2, text). XPRES participants were followed for 12 months, or until the end of TB treatment, whichever was later. The final follow-up visits for XPRES enrollees were in June 2015.

\section{Development and temporal validation of the prediction model}

A clinically useful prediction model should demonstrate accurate prediction of the outcome in data other than that in which the model was developed. Therefore, we split the XPRES dataset in a 1:1 ratio using the midpoint of enrollment at each of the 22 study clinics to create the derivation dataset (the first $50 \%$ of enrollees) and the temporal validation dataset (the second $50 \%$ of enrollees) [17].

\section{Outcome}

The outcome of interest for both the XPRES trial and this analysis was early (6-month) ART mortality. We implemented intensive efforts to ascertain true mortality outcomes among participants, with deaths and date of death either passively reported to the clinic by friends or relatives or actively ascertained if the client had missed an appointment or was considered lost to follow-up (LTFU) (> 60 days late for a scheduled appointment) [18]. Initial efforts to ascertain outcomes of clients who missed an appointment by $\geq 1$ day included up to five phone calls to the client or contact and up to two home visits. In addition, for all clients unreachable by phone or home visit who met the LTFU definition, vital status was ascertained through national Death Registry review. By law, since 1969, all deaths need to be registered in the Death Registry, which is maintained by the Botswana Civil and National Registration Office. Available data shows Death Registry data completeness to be high [16].

\section{Candidate predictor variables}

We selected candidate predictor variables for potential inclusion in the predictive model based on prior publications, and the need for variables to be reproducible, objective, and readily available in resource-constrained clinic settings [19]. We considered variables known to be associated with mortality including age, sex (coded as male, pregnant female, and non-pregnant female [20]), education level, employment status, smoking history, prior TB treatment, number of WHO TB symptoms, weight, body mass index (BMI) (weight/height ${ }^{2}$ ), hemoglobin level, CD4 count, temperature at ART 
initiation in degrees Celsius, and respiratory rate at ART initiation [20-23].

Within the derivation dataset, we performed univariable analyses assessing the association of each variable with risk of mortality using logistic regression. Because follow-up of all XPRES and TBFT enrollees was complete with true ascertainment of 6-month mortality outcomes, 6-month risk was preferred to rate [16]. Continuous variables were assessed for non-linearity with log odds of death using fractional polynomials, as well as by comparing Akaike's Information Criteria and Bayesian Information Criteria between models with linear or fractional polynomial terms. Where non-linearity was observed, the appropriate fractional polynomial terms were included in the logistic regression. We also examined scatter plots of linear and transformed continuous variables and risk of mortality to assess inflection points which might inform appropriate categorization of continuous variables.

For the multivariable analysis, a complete case analysis, whereby observations with missing data for key variables were dropped, was chosen because few data $(<10 \%)$ were missing. To generate a parsimonious multivariable model, we used a stepwise backward elimination approach, starting with all candidate variables and excluding variables sequentially if $p>0.01$ using both automatic and manual approaches. We also explored how findings changed using a forward stepwise addition approach. Where two or more predictors were highly correlated, only one was selected, to simplify the prognostic model. We created two multivariable models: one in which CD4 was purposefully excluded and one in which CD4 count was included as a candidate variable to reflect situations where CD4 is either unavailable or available at the clinic. Plausible interactions between covariates (e.g., between CD4 and age) were assessed using the likelihood ratio test.

In both the derivation and temporal validation datasets, we assessed multivariable model calibration (i.e., the agreement between probability of 6-month mortality predicted by the model and observed probability of death within quantiles of predicted risk) graphically in a calibration plot [17] and statistically using the Hosmer-Lemeshow test. We also assessed discrimination, the ability of our model to differentiate patients who died by 6 months of ART vs. those who did not, using the area under the receiveroperating characteristic (AUROC) curve, also referred to as the C-statistic or C-index. AUROC values of 0.7 to $0.79,0.8$ to 0.89 , and $\geq 0.9$ are respectively considered acceptable, excellent, and outstanding discrimination [24].

Two final multivariable models were used to generate the two clinical scores (i.e., the CD4-independent and CD4-dependent scores). For these models, continuous variables were categorized in a clinically meaningful manner based on their functional form and information from the published literature. Each beta coefficient from this logistic regression model was then rescaled to generate a clinical score by dividing each coefficient by the smallest positive model coefficient and rounding to the nearest integer. The total number of points was summed for each participant to calculate their total clinical score.

\section{External validation of risk scores}

To externally validate the clinical risk score, we used data collected independently from the TBFT trial from

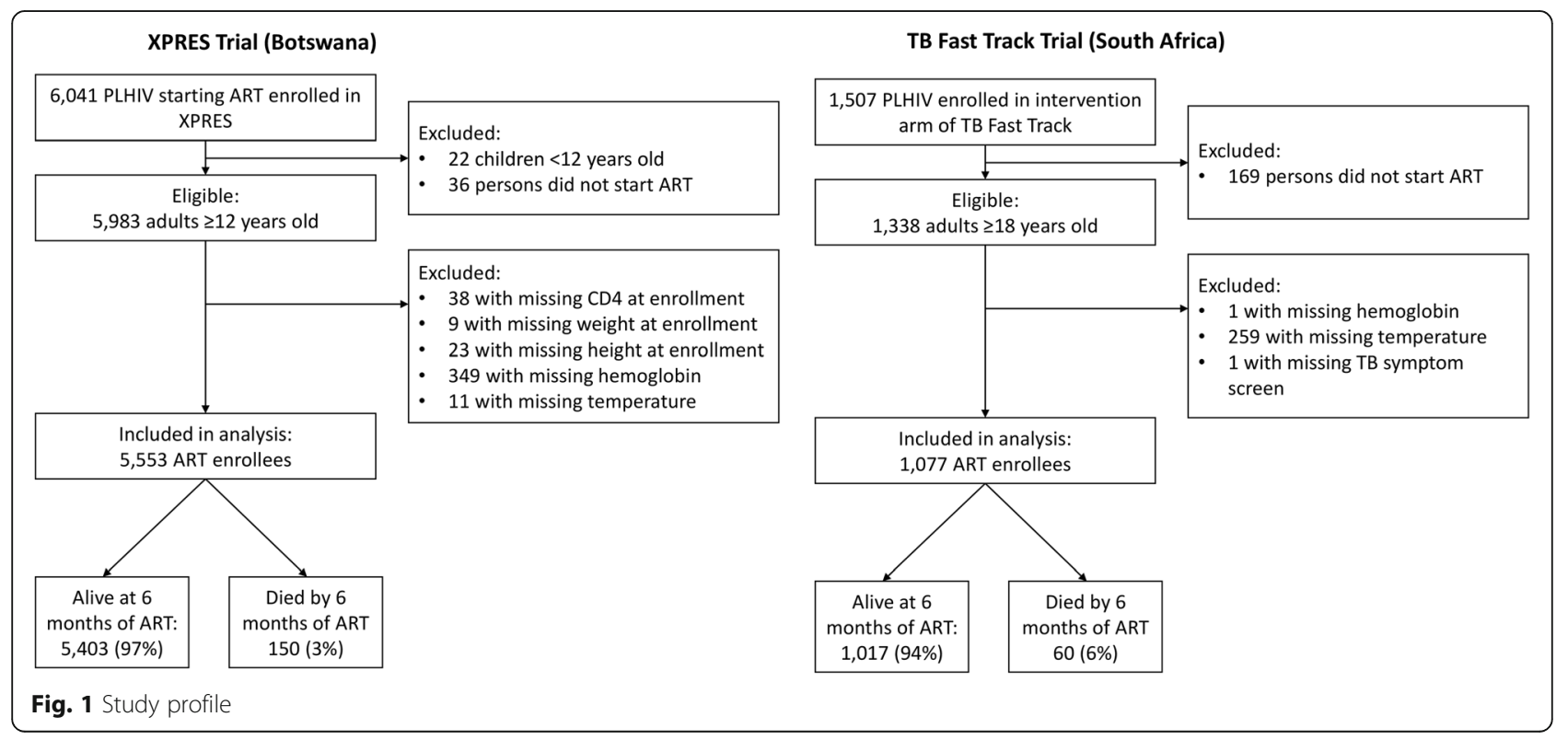


Table 1 Comparison of characteristics of antiretroviral therapy enrollees between internal derivation, internal validation, and external validation datasets

\begin{tabular}{|c|c|c|c|c|c|c|c|}
\hline \multirow{2}{*}{ Demographics } & & \multicolumn{2}{|c|}{$\begin{array}{l}\text { Internal derivation } \\
\text { dataset }(N=2838)\end{array}$} & \multicolumn{2}{|c|}{$\begin{array}{l}\text { Internal validation } \\
\text { dataset }(N=2715)\end{array}$} & \multicolumn{2}{|c|}{ 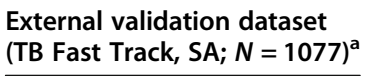 } \\
\hline & & $n$ & Median or $\%$ & $n$ & Median or $\%$ & $n$ & Median or $\%$ \\
\hline Age, years, median (IQR) & & 2838 & $33.8(28.6-40.9)$ & 2715 & $34.0(28.6-41.4)$ & 1077 & $38.0(32.0-44.0)$ \\
\hline Female, $n, \%$ & & 1938 & $68 \%$ & 1779 & $66 \%$ & 590 & $55 \%$ \\
\hline If female, pregnant, $n, \%$ & & 520 & $27 \%$ & 551 & $31 \%$ & 0 & $0 \%$ \\
\hline \multirow[t]{3}{*}{ Marital status, $n, \%$} & Married/civil union & 300 & $11 \%$ & 265 & $10 \%$ & & \\
\hline & Single & 2441 & $86 \%$ & 2346 & $86 \%$ & & \\
\hline & Widowed/divorced & 97 & $3 \%$ & 104 & $4 \%$ & & \\
\hline Smoking history (ever smoked), $n, \%$ & & 517 & $18 \%$ & 551 & $20 \%$ & 238 & $22 \%$ \\
\hline Currently employed, n, \% & & 1270 & $45 \%$ & 1286 & $47 \%$ & & \\
\hline \multirow[t]{4}{*}{ Education, $n, \%$} & None & 196 & $7 \%$ & 200 & $7 \%$ & & \\
\hline & Primary & 687 & $24 \%$ & 596 & $22 \%$ & & \\
\hline & Secondary & 1734 & $61 \%$ & 1641 & $60 \%$ & & \\
\hline & Higher & 221 & $8 \%$ & 278 & $10 \%$ & & \\
\hline \multicolumn{8}{|l|}{ HIV/TB history } \\
\hline Previous TB treatment, $n, \%$ & Yes & 277 & $10 \%$ & 262 & $10 \%$ & & \\
\hline \multicolumn{8}{|l|}{ WHO TB symptoms, $n, \%$} \\
\hline Cough & Yes & 495 & $17 \%$ & 547 & $20 \%$ & 463 & $43 \%$ \\
\hline Weight loss & Yes & 599 & $21 \%$ & 555 & $20 \%$ & 797 & $74 \%$ \\
\hline Fever & Yes & 259 & $9 \%$ & 245 & $9 \%$ & 314 & $29 \%$ \\
\hline Night sweats & Yes & 273 & $10 \%$ & 253 & $9 \%$ & 348 & $32 \%$ \\
\hline \multirow[t]{5}{*}{ Number of WHO TB symptoms, $n, \%$} & 0 & 1975 & $70 \%$ & 1911 & $70 \%$ & 230 & $21 \%$ \\
\hline & 1 & 427 & $15 \%$ & 349 & $13 \%$ & 285 & $26 \%$ \\
\hline & 2 & 202 & $7 \%$ & 216 & $8 \%$ & 226 & $21 \%$ \\
\hline & 3 & 141 & $5 \%$ & 137 & $5 \%$ & 178 & $17 \%$ \\
\hline & 4 & 93 & $3 \%$ & 102 & $4 \%$ & 158 & $15 \%$ \\
\hline \multicolumn{8}{|l|}{ Clinical characteristics } \\
\hline WHO stage III/IV, n, \% & & 354 & $12 \%$ & 307 & $11 \%$ & & \\
\hline CD4 (cells/ $\mu \mathrm{L})$ & Median (IQR) & 2838 & $245(143-315)$ & 2715 & $240(134-319)$ & 1077 & $72(36-110)$ \\
\hline Weight (kilograms) & Median (IQR) & 2838 & $58.8(51.8-68.2)$ & 2715 & $59.7(52.8-69.0)$ & 1077 & $57.9(50.8-67.0)$ \\
\hline BMI (weight/height²) & Median (IQR) & 2838 & $21.5(18.9-24.9)$ & 2715 & $21.6(19.1-25.0)$ & 1077 & $21.3(18.8-25.0)$ \\
\hline Hemoglobin (g/dL) & Median (IQR) & 2838 & $11.9(10.4-13.2)$ & 2715 & $12.0(10.7-13.4)$ & 1077 & $11.3(9.7-13.0)$ \\
\hline Temperature (degrees Celsius) & Median (IQR) & 2838 & $36.2(35.8-36.5)$ & 2715 & $36.2(35.8-36.6)$ & 1077 & $36.4(36.0-36.7)$ \\
\hline Respiratory rate (breaths/min) & Median (IQR) & 2838 & $19(18-20)$ & 2715 & $19(18-20)$ & & \\
\hline Heart rate (beats/min) & Median (IQR) & 2838 & $84(75-94)$ & 2715 & $84(75-95)$ & & \\
\hline \multicolumn{8}{|l|}{ Mortality within 6 months } \\
\hline Cumulative incidence, $n, \%$ & & 83 & $2.9 \%$ & 67 & $2.5 \%$ & 60 & $6 \%$ \\
\hline Time to death (days) & Median (IQR) & 83 & $50(25-105)$ & 67 & $46(16-87)$ & 60 & $55(30-112)$ \\
\hline
\end{tabular}

Abbreviations: IQR interquartile range, $T B$ tuberculosis, WHO World Health Organization, $C D 4 C D 4^{+}$T cell count, $T B$ tuberculosis, $B M I$ body mass index, SA South Africa

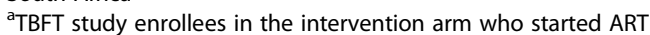

SA [14]. TBFT was an open-label cluster randomized controlled trial, recruiting individuals from 24 primary healthcare clinics in SA. All outpatient, HIV-positive adults (aged $\geq 18$ years) with CD4 counts $<150 / \mu \mathrm{L}$, no
TB treatment in the past 3 months, and no ART in the last 6 months were eligible. In the intervention clinics, participants were classified by a study algorithm as having high, medium, or low TB risk. High TB risk patients 


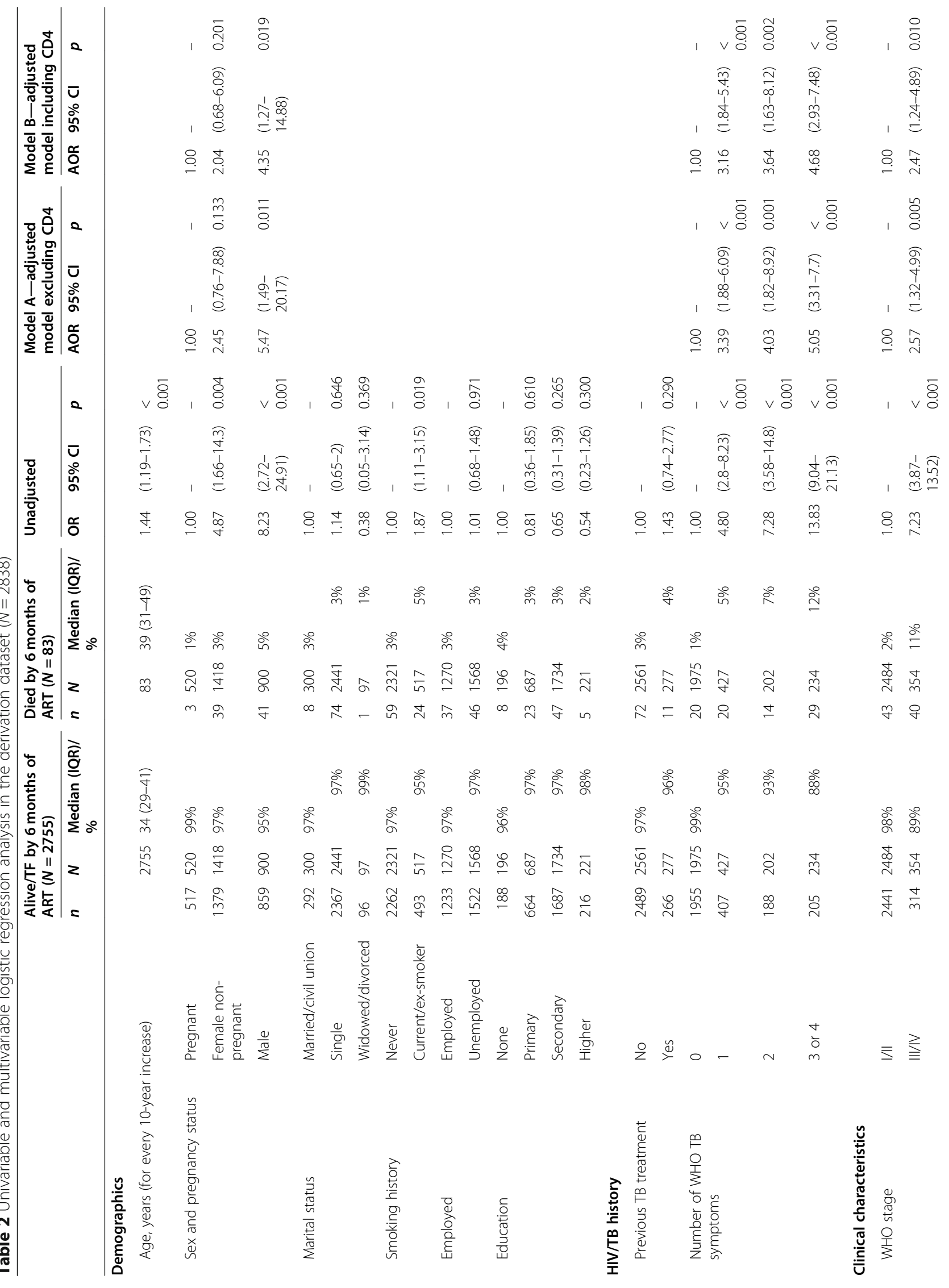




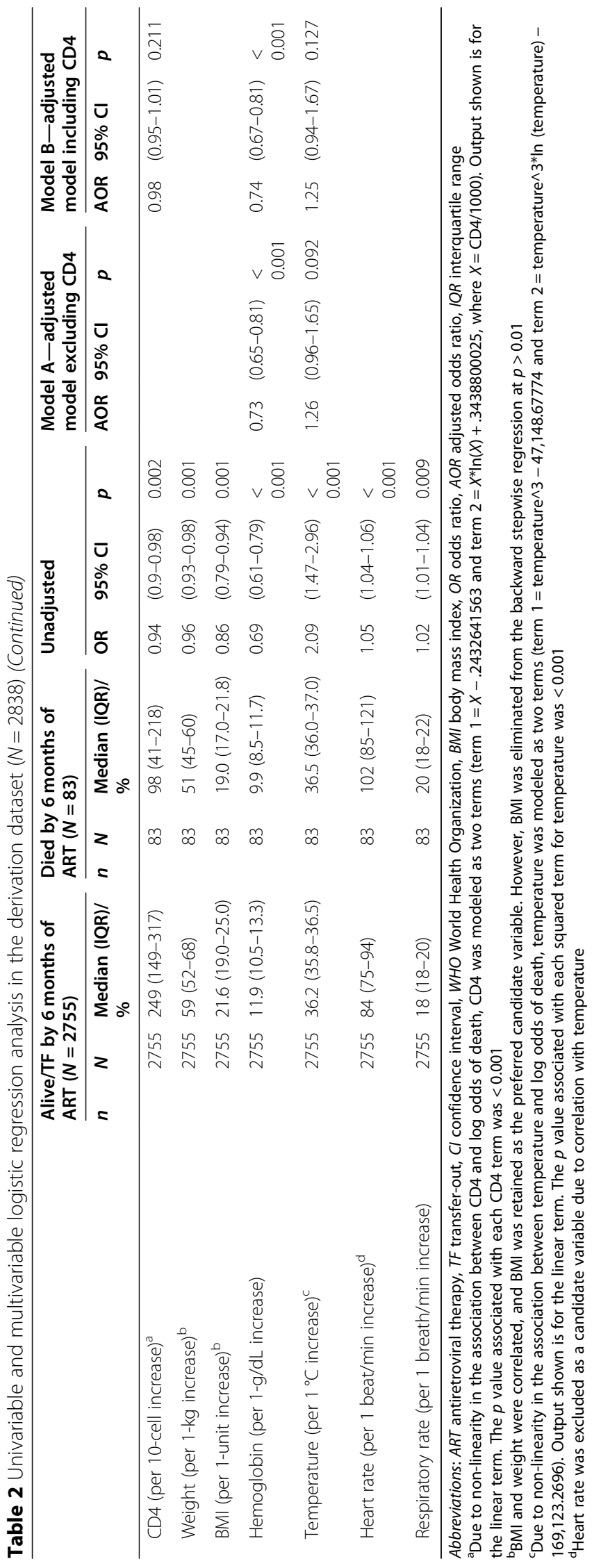


(i.e., those with positive lateral flow urine lipoarabinomannan assay [LF-LAM], BMI $<18.5$, or hemoglobin < $10 \mathrm{~g} / \mathrm{dL}$ ) started TB treatment immediately followed by ART 2 weeks later. Medium TB risk participants (i.e., those with $\geq 1$ WHO TB symptom only) were recommended to have symptom-guided TB investigation. Low TB risk patients (no TB symptoms or high-risk criteria) were recommended to start ART immediately. The primary outcome was all-cause mortality at 6 months after enrollment. We restricted this analysis to intervention arm participants, for whom key variables such as temperature at enrollment were available, and to those patients who started ART, since the outcome of interest was mortality within the first 6 months of ART. The median time from trial enrollment to ART start in the intervention arm was 21 days. Participants were enrolled in TBFT between December 19, 2012, and December 18, 2014. The clinical risk score for mortality was calculated by assigning the same "points" to variables as for the derivation cohort.

For both the XPRES cohort (combined derivation and validation datasets), and the TBFT datasets, we explored how sensitivity, specificity, positive predictive value
(PPV), negative predictive value (NPV), and AUROC curve values varied with increasing clinical score in terms of predicting 6-month mortality and compared this screening accuracy and discrimination performance with the WHO eligibility criteria for advanced disease. Three risk groups were created to visualize increasing 6month ART mortality risk with increasing clinical score, and the percentage of ART enrollees falling into each risk group. Kaplan-Meier (K-M) curves were used to visualize rates of early mortality within the three risk groups.

All analyses were conducted using STATA 16 (StataCorp, 2009, Stata Statistical Software, Release 16, College Station, TX). The study is reported in concordance with TRIPOD guidance for multivariable prediction models (see Additional file 3, a table with the TRIPOD checklist).

\section{Results}

From the XPRES cohort, 5553 eligible ART enrollees with complete data for candidate predictors were included in the analysis (Fig. 1). Overall, 150 (3\%) of 5553 ART enrollees died within 6 months of ART initiation.
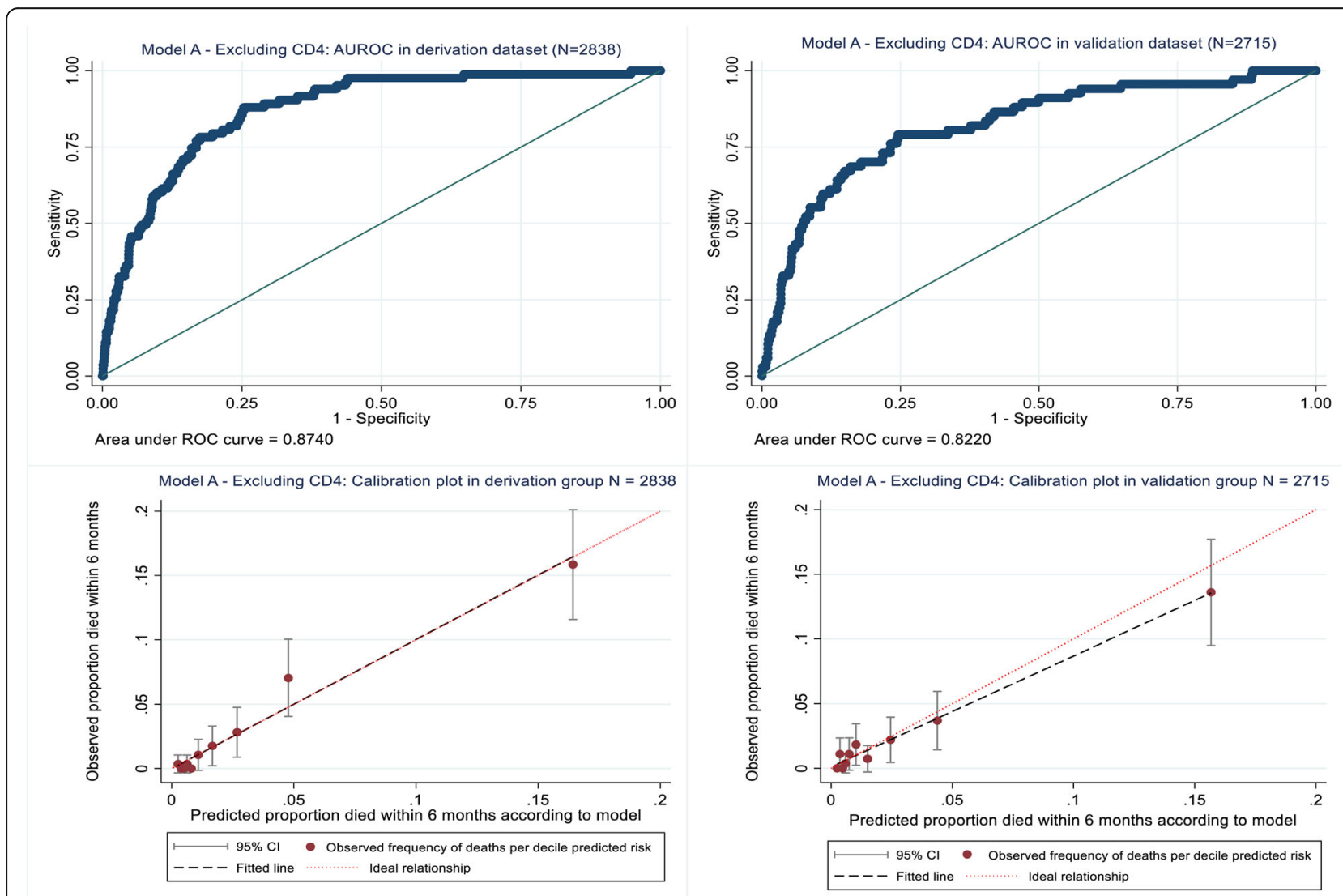

Fig. 2 Model A (excluding CD4) development and performance in the internal derivation and validation datasets respectively 
Internal derivation and temporal validation datasets

From the XPRES cohort, the internal derivation $(N=$ $2838)$ and temporal validation $(N=2715)$ datasets were created (Table 1). Key characteristics including median age (34), percentage female (66-68\%), median CD4 $(240-245 / \mu \mathrm{L})$, and 6 -month mortality $(2.5-2.9 \%)$ were similar between internal XPRES derivation and validation datasets (Table 1). Notable differences between the XPRES cohorts and TBFT external validation cohort were that the TBFT cohort had a higher prevalence of markers of advanced disease, with a higher prevalence of $\geq 1$ TB symptom (79\% versus $30 \%$ ), lower median CD4 count (72 versus $240-245 / \mu \mathrm{L}$ ), and higher incidence of all-cause 6-month ART mortality (6.0\% versus $2.5-2.9 \%)$ (Table 1).

\section{Development of the regression model}

Table 2 summarizes the results of univariable and multivariable logistic regression model development. Although the linear continuous variables of age, weight, BMI, heart rate, and respiratory rate, as well as history of smoking, were associated with 6-month mortality in univariable analysis, these variables were either dropped as candidate variables due to correlation (i.e., weight and heart rate were dropped due to correlation with BMI and temperature respectively) or eliminated in the stepwise backward elimination approach due to $p$ values in multivariable analysis $>0.01$.

The final multivariable model A (which simulated the situation where CD4 is unavailable) included sex, number of WHO TB symptoms, WHO disease stage, hemoglobin concentration (continuous, linear term), and temperature (modeled as two transformed terms following output from the multivariable fractional polynomial analysis) (Table 2). In the final multivariable model $\mathrm{B}$ (which simulated the situation where CD4 is available), the same variables included in model A plus CD4 were included (Table 2).

\section{Internal validation of final regression models}

The Hosmer-Lemeshow statistics for model A (excluding CD4) on both the derivation $(p=0.381)$ and validation $(p=0.210)$ datasets indicated good model fit (see Additional file 4, table showing results of HosmerLemeshow tests). Similarly, the calibration curves (Fig. 2) indicate adequate prediction performance for the 10 risk groups in terms of the predicted number of deaths
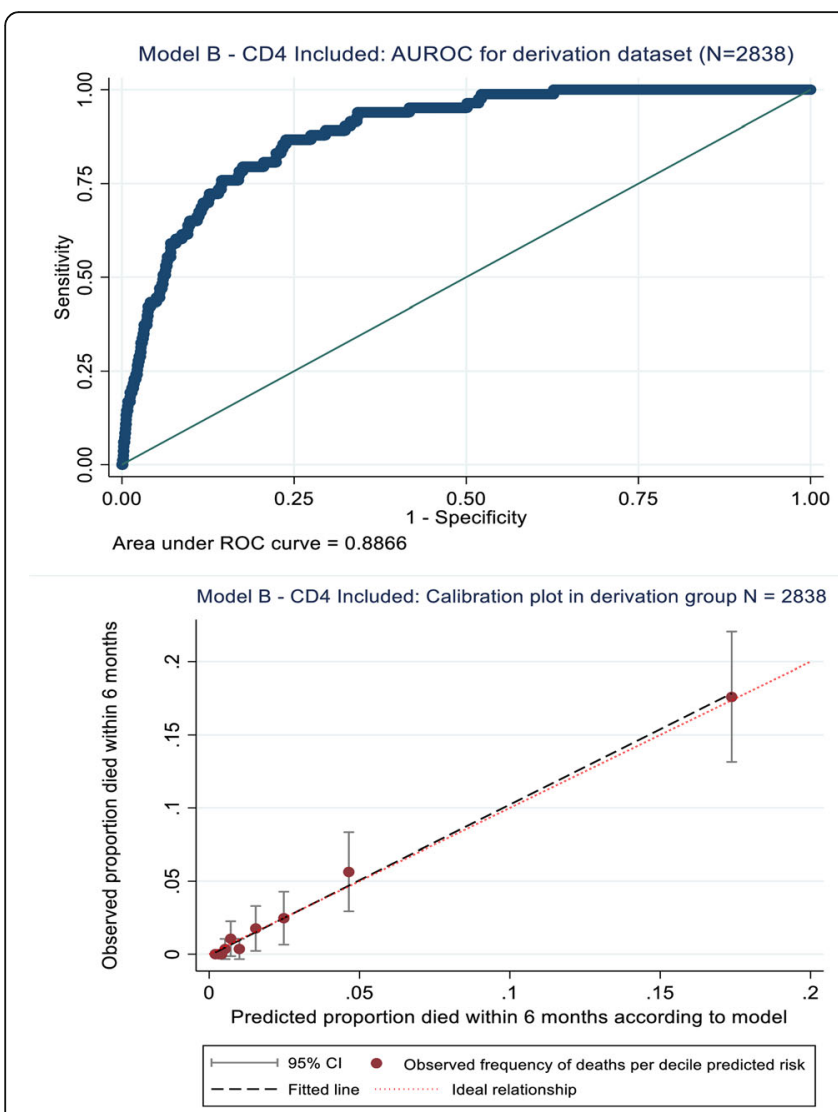

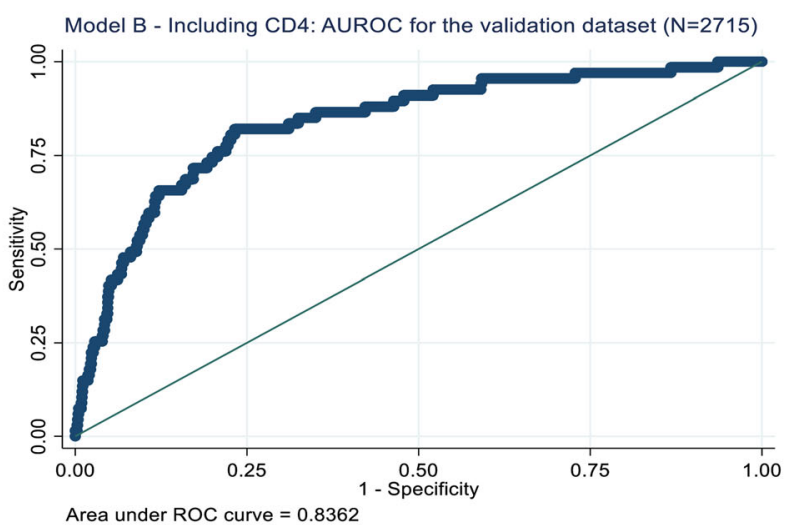

Model B - CD4 Included: Calibration plot in validation group N $=2715$

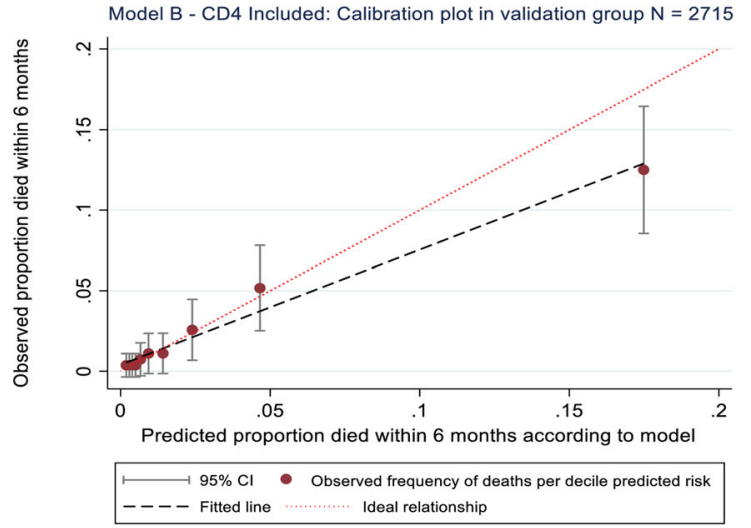

Fig. 3 Model B (including CD4) development and performance in the internal derivation and validation datasets respectively 
Table 3 Multivariable model and clinical score generation from the derivation dataset $(N=2838)$

\begin{tabular}{|c|c|c|c|c|c|c|c|c|c|c|c|}
\hline & & \multicolumn{5}{|c|}{ Predictor-model A (excluding CD4) } & \multicolumn{5}{|c|}{ Predictor-model B (including CD4) } \\
\hline & & $\overline{\mathrm{AOR}}$ & $95 \% \mathrm{Cl}$ & $\begin{array}{l}p \\
\text { value }\end{array}$ & $\begin{array}{l}\text { B } \\
\text { coefficient }\end{array}$ & Score & AOR & $95 \% \mathrm{Cl}$ & $\begin{array}{l}p \\
\text { value }\end{array}$ & $\begin{array}{l}\text { B } \\
\text { coefficient }\end{array}$ & Score \\
\hline \multirow[t]{3}{*}{ Sex and pregnancy status } & Female (pregnant) & 1.00 & - & - & - & 0 & 1.00 & - & - & - & 0 \\
\hline & $\begin{array}{l}\text { Female (non- } \\
\text { pregnant) }\end{array}$ & 1.94 & $(0.58-6.50)$ & 0.283 & 0.66 & 1 & 1.71 & $(0.53-5.52)$ & 0.373 & 0.53 & 1 \\
\hline & Male & 3.54 & $\begin{array}{l}(0.95- \\
13.26)\end{array}$ & 0.060 & 1.26 & 2 & 2.93 & $\begin{array}{l}(0.82- \\
10.44)\end{array}$ & 0.097 & 1.08 & 2 \\
\hline \multirow{2}{*}{$\begin{array}{l}\text { Number of WHO TB } \\
\text { symptoms }\end{array}$} & 0 & 1.00 & - & - & - & 0 & 1.00 & - & - & - & 0 \\
\hline & $\geq 1$ & 3.65 & $(2.24-5.97)$ & $\begin{array}{l}< \\
0.001\end{array}$ & 1.30 & 2 & 3.33 & $(2.06-5.38)$ & $<0.001$ & 1.20 & 2 \\
\hline \multirow[t]{2}{*}{ WHO stage } & $|/| \mid$ & 1.00 & - & - & - & 0 & 1.00 & - & - & - & 0 \\
\hline & III/IV & 2.72 & $(1.42-5.20)$ & 0.003 & 1.00 & 2 & 2.55 & $(1.32-4.92)$ & 0.005 & 0.94 & 2 \\
\hline \multirow[t]{2}{*}{ Temperature at enrollment } & $\leq 37.5^{\circ} \mathrm{C}$ & 1.00 & - & - & - & 0 & 1.00 & - & - & - & 0 \\
\hline & $>37.5^{\circ} \mathrm{C}$ & 3.39 & $(1.65-6.96)$ & 0.001 & 1.22 & 2 & 3.37 & $(1.56-7.26)$ & 0.002 & 1.21 & 2 \\
\hline \multirow[t]{2}{*}{ CD4 count } & $\geq 200 / \mu \mathrm{L}$ & - & - & - & - & N/A & 1.00 & - & - & - & 0 \\
\hline & $<200 / \mu \mathrm{L}$ & - & - & - & - & N/A & 2.05 & $(1.20-3.50)$ & 0.009 & 0.72 & 1 \\
\hline \multirow[t]{3}{*}{ Anemia status $^{a}$} & No anemia & 1.00 & - & - & - & 0 & 1.00 & - & - & - & 0 \\
\hline & $\begin{array}{l}\text { Mild/moderate } \\
\text { anemia }\end{array}$ & 5.03 & $(2.57-9.87)$ & $\begin{array}{l}< \\
0.001\end{array}$ & 1.62 & 2 & 4.58 & $(2.37-8.84)$ & $<0.001$ & 1.52 & 3 \\
\hline & Severe anemia & 9.42 & $\begin{array}{l}(3.43- \\
25.89)\end{array}$ & $\begin{array}{l}< \\
0.001\end{array}$ & 2.24 & 3 & 8.02 & $\begin{array}{l}(3.04- \\
21.14)\end{array}$ & $<0.001$ & 2.08 & 4 \\
\hline
\end{tabular}

Abbreviations: $A O R$ adjusted odds ratio, $C l$ confidence interval, WHO World Health Organization

${ }^{a}$ Anemia severity was classified according to World Health Organization criteria as follows: no anemia, hemoglobin level of $\geq 13.0 \mathrm{~g} / \mathrm{dL}$ for men, $\geq 12.0 \mathrm{~g} / \mathrm{dL}$ for non-pregnant females, and $\geq 11.0 \mathrm{~g} / \mathrm{dL}$ for pregnant females; mild/moderate anemia, 8.0 to $<13.0 \mathrm{~g} / \mathrm{dL}$ for men, 8.0 to $<12.0 \mathrm{~g} / \mathrm{dL}$ for non-pregnant women, and 7.0 to $<11.0 \mathrm{~g} / \mathrm{dL}$ for pregnant women; and severe anemia, $<8.0 \mathrm{~g} / \mathrm{dL}$ for males and non-pregnant females and $<7.0 \mathrm{~g} / \mathrm{dL}$ for pregnant women

within 6 months of ART versus the observed number of deaths. In addition, the AUROC curve values for the derivation $(0.874)$ and validation $(0.822)$ datasets indicated excellent discrimination (Fig. 2).
The Hosmer-Lemeshow statistics for model B (including CD4) on both the derivation $(p=0.735)$ and validation $(p=0.677)$ datasets also indicated good model fit (see Additional file 4, table showing results of Hosmer-

\begin{tabular}{|c|c|c|c|c|c|c|c|}
\hline \multirow[b]{2}{*}{ Risk Factor } & \multicolumn{2}{|l|}{ NO } & \multicolumn{2}{|c|}{ Is CD4 Count Currently Available? } & YES & \multirow[b]{2}{*}{$\begin{array}{c}\text { Associated } \\
\text { points }\end{array}$} & \multirow[b]{2}{*}{ Assigned score } \\
\hline & Category & $\begin{array}{l}\text { Associated } \\
\text { points }\end{array}$ & Assigned score & Risk Factor & Category & & \\
\hline \multirow{3}{*}{ Gender } & Pregnant Female & 0 & & \multirow{3}{*}{ Gender } & Pregnant Female & 0 & \\
\hline & Non-pregnant Female & 1 & & & Non-pregnant Female & 1 & \\
\hline & Male & 2 & & & Male & 2 & \\
\hline \multirow{2}{*}{$\begin{array}{l}\text { No. of WHO } \\
\text { TB symptoms }\end{array}$} & Zero & 0 & & \multirow{2}{*}{$\begin{array}{l}\text { No. of WHO } \\
\text { TB symptoms }\end{array}$} & Zero & 0 & \\
\hline & $\geq 1$ & 1 & & & $\geq 1$ & 2 & \\
\hline \multirow{2}{*}{$\begin{array}{l}\text { WHO Disease } \\
\text { stage }\end{array}$} & | or II & 0 & & \multirow{2}{*}{$\begin{array}{l}\text { WHO Disease } \\
\text { stage }\end{array}$} & | or II & 0 & \\
\hline & III or IV & 2 & & & III or IV & 2 & \\
\hline \multirow{2}{*}{$\begin{array}{l}\text { Temperature } \\
\left({ }^{\circ} \mathrm{C}\right)\end{array}$} & $\leq 37.5$ & 0 & & \multirow{2}{*}{$\begin{array}{l}\text { Temperature } \\
\left({ }^{\circ} \mathrm{C}\right)\end{array}$} & $\leq 37.5$ & 0 & \\
\hline & $>37.5$ & 2 & & & $>37.5$ & 2 & \\
\hline \multirow{6}{*}{$\begin{array}{l}\text { Hemoglobin } \\
\text { Level }\end{array}$} & No anemia & 0 & & \multirow{2}{*}{$\begin{array}{l}\text { CD4 Count } \\
\text { (cells/ } \mu \mathrm{L})\end{array}$} & $\geq 200$ & 0 & \\
\hline & Mild/Mod. anemia & 2 & & & $<200$ & 1 & \\
\hline & Severe anemia & 3 & & \multirow{3}{*}{$\begin{array}{l}\text { Hemoglobin } \\
\text { Level }\end{array}$} & No anemia & 0 & \\
\hline & \multicolumn{3}{|c|}{ Total } & & Mild/Mod. anemia & 3 & \\
\hline & & & & & Severe anemia & 4 & \\
\hline & & & & & & Total & \\
\hline
\end{tabular}


Lemeshow tests), with calibration curves (Fig. 3) indicating adequate prediction performance for the 10 risk groups. However, in the highest risk group (risk group 10), model B overestimated mortality risk in the validation dataset, with 48 deaths predicted but only 34 observed (see Additional file 4, table showing results of Hosmer-Lemeshow tests). In addition, the AUROC curve values for the derivation (0.887) and validation datasets (0.836) indicated excellent discrimination (Fig. 3).

\section{Transformation from the regression model to clinical} score

We used WHO advanced disease classifications for WHO stage (stage III or IV), and CD4 count $(<200$ cells $/ \mu \mathrm{L})$. Anemia severity in adults was classified according to WHO criteria as follows [25]: no anemia was defined as hemoglobin $\geq 13.0 \mathrm{~g} / \mathrm{dL}$ for men, $\geq 12.0 \mathrm{~g} / \mathrm{dL}$ for non-pregnant females, and $\geq 11.0 \mathrm{~g} / \mathrm{dL}$ for pregnant females; mild/moderate anemia was defined as 8.0 to < $13.0 \mathrm{~g} / \mathrm{dL}$ for men, 8.0 to $<12.0 \mathrm{~g} / \mathrm{dL}$ for non-pregnant

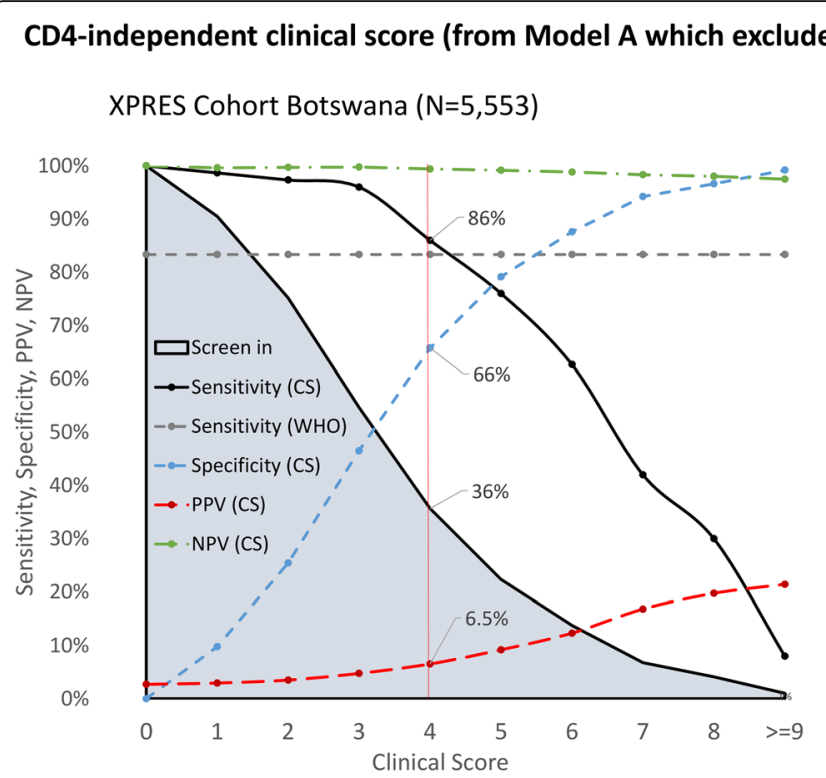

TBFT Cohort SA $(\mathrm{N}=1,077)$

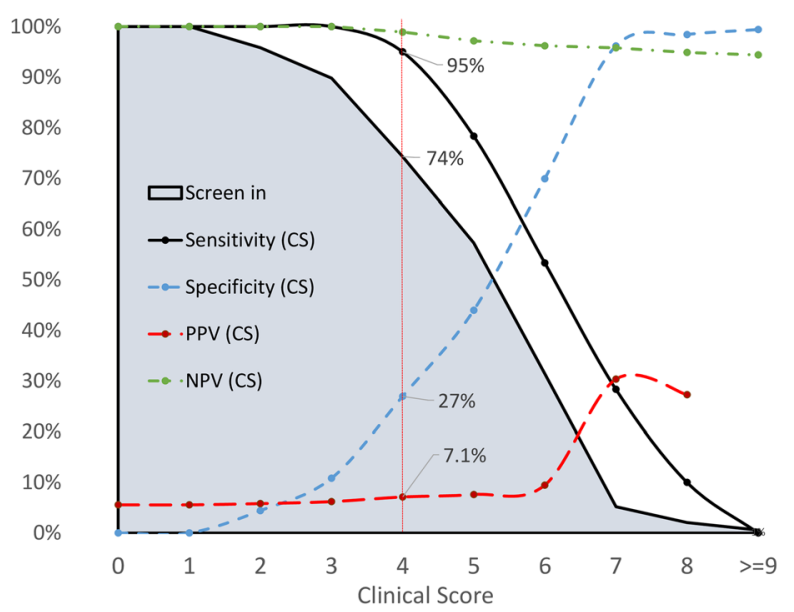

CD4-dependent clinical score (from Model B which includes CD4)

XPRES Cohort Botswana $(\mathrm{N}=5,553)$

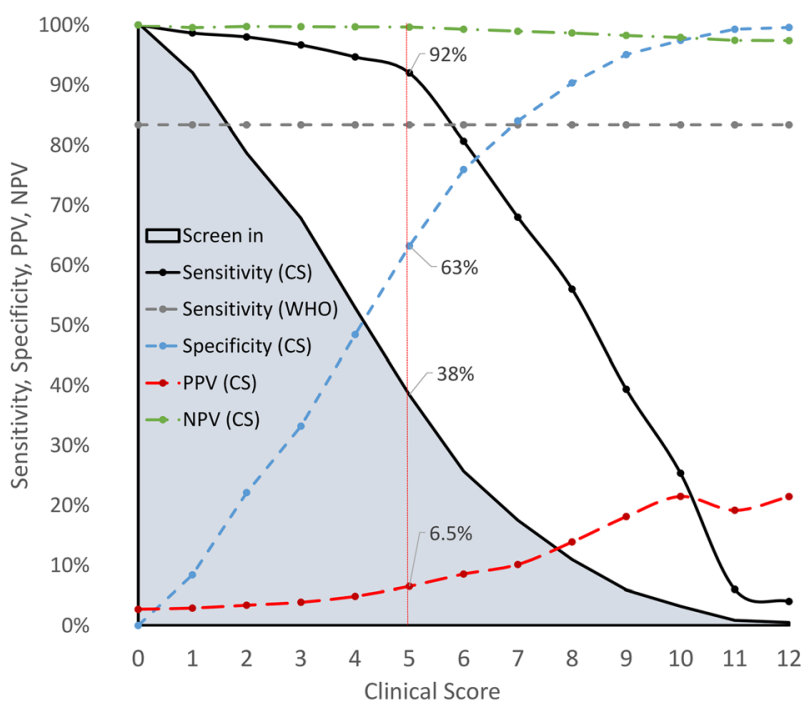

TBFT Cohort SA $(\mathrm{N}=1,077)$

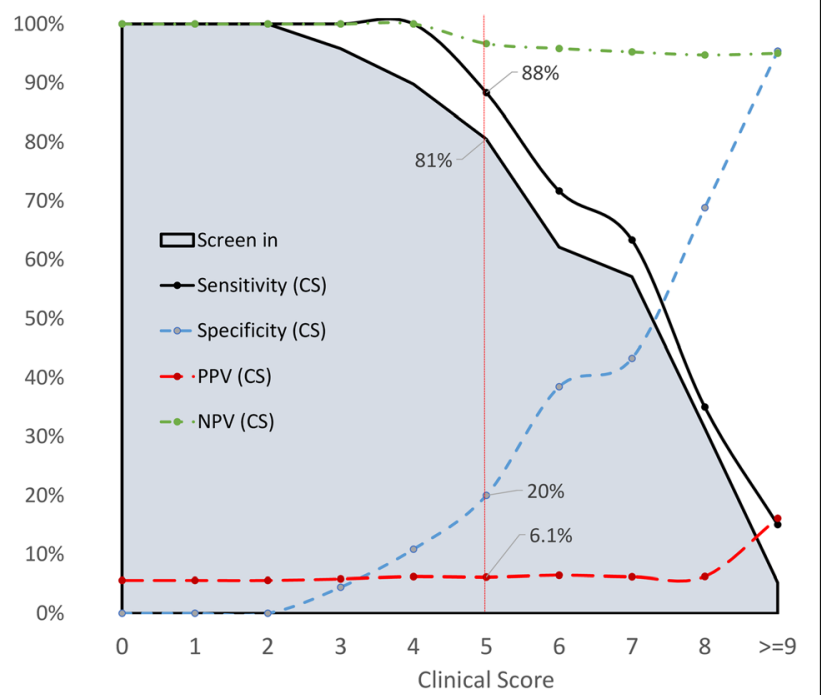

Fig. 5 Sensitivity, specificity, PPV, and NPV of clinical score in predicting 6-month mortality in XPRES dataset ( N=5553) and external validation TB Fast Track Dataset $(N=1077)$ for models A (excluding CD4) and B (including CD4) 
females, and 7.0 to $<11.0 \mathrm{~g} / \mathrm{dL}$ for pregnant females; and severe anemia was defined as $<8.0 \mathrm{~g} / \mathrm{dL}$ for males and non-pregnant females and $<7.0 \mathrm{~g} / \mathrm{dL}$ for pregnant females. Temperature was classified as $\leq 37.5^{\circ} \mathrm{C}$ versus $>$ $37.5^{\circ} \mathrm{C}$ based on the observed distribution of mortality risk as measured temperature increased (see Additional file 5, figure of association between temperature and risk of death), and a common definition of a lowgrade fever or higher $\left(>37.5^{\circ} \mathrm{C}\right)$ [26]. The multivariable model with categorization of these continuous variables in the derivation dataset is presented in Table 3. Because heart rate might be more easily available in LMIC settings than temperature, we also created an alternate clinical score where heart rate replaced temperature (see Additional file 6, table showing alternate clinical score). In this alternate score, we used heart rate cut-offs of > 120 versus $\leq 120$ beats/minute, which were informed by both prior published literature [22, 27] and observed inflection points in the association between heart rate and risk of death (see Additional file 5, figure of association between heart rate and risk of death).

Model A, categorized in this way, retained statistically excellent discrimination in both derivation (AUROC 0.867 ) and validation datasets (AUROC 0.818), and the Hosmer-Lemeshow statistic $p$ values were 0.269 in the derivation and 0.334 in the validation datasets indicating good calibration. Similarly, model B AUROC statistics were 0.874 in the derivation and 0.830 in the validation datasets, with Hosmer-Lemeshow statistic $p$ values of 0.367 and 0.307 in the derivation and validation datasets, respectively, indicating good model fit. The clinical scores that could be used in clinic settings to identify those at risk of early 6-month mortality, depending on the availability of CD4 count, are illustrated in Fig. 4.

\section{External validation of risk scores}

The clinical score for each predictor was generated, and the possible range for the total score was 0 to 11 for model A and 0 to 13 for model B (see Additional file 7, tables showing performance of clinical scores). Figure 5 shows the performance of the two clinical scores at different cut-offs, in terms of sensitivity, specificity, negative predictive value (NPV), positive predictive value (PPV), and percentage of enrollees screened into ART care intensification.

For the CD4-independent clinical score derived from model A, (Fig. 5) among XPRES enrollees, a clinical score of $\geq 4$ would screen in $36 \%$ of ART enrollees into a care intensification pathway, providing $86 \%$ sensitivity and $66 \%$ specificity in detecting those at risk for early mortality, whereas the WHO advanced disease eligibility criteria $(\mathrm{CD} 4<200 / \mu \mathrm{L}$ or WHO stage III/IV) would screen in $44 \%$ of ART enrollees, providing $83 \%$ sensitivity and $58 \%$ specificity. Notably, if the WHO advanced disease eligibility criterion of WHO stage III/IV only was used since CD4 is unavailable, $12 \%$ of ART enrollees would be screened into an ART care intensification pathway, with only $48 \%$ sensitivity in detecting 6-month mortality and $89 \%$ specificity. All 72 XPRES patients with WHO stage III/IV who died by 6 months of ART would also be screened into intensification of care pathways using a clinical score cut-off of $\geq 4$. Among TBFT enrollees, the clinical score of $\geq 4$ would screen in $74 \%$ of ART enrollees, providing 95\% sensitivity and $27 \%$ specificity in detecting early mortality, versus the WHO advanced disease eligibility criteria which would screen in 100\% of ART enrollees, with 100\% sensitivity but $0 \%$ specificity.

For the CD4-dependent clinical score derived from model B, a clinical score of $\geq 5$ would screen in $38 \%$ of ART enrollees into a care intensification pathway, providing $92 \%$ sensitivity and $63 \%$ specificity in detecting those at risk for early mortality. Ninety-seven percent (121 of 125) XPRES patients with either a CD $4<200 / \mu \mathrm{L}$ or WHO stage III/IV who died by 6 months would be screened into intensification of care pathways using a clinical score $\geq 5$. Among TBFT enrollees, the clinical score of $\geq 5$ would screen in $81 \%$ of ART enrollees, providing $88 \%$ sensitivity and $20 \%$ specificity in detecting early mortality. For both CD4-dependent and CD4independent clinical scores, screening accuracy characteristics were very similar when heart rate replaced temperature in the clinical score (see Additional file 8, figure of screening accuracy for the alternate clinical scores).

The AUROC for CD4-independent (0.845) and CD4dependent (0.852) clinical scores remained high for XPRES enrollees but was low for TB FT enrollees $(0.568$ for CD4-independent and 0.569 for CD4-dependent scores) (see Additional file 9, figure of AUROC for clinical score performance).

For the CD4-independent clinical score, risk scores were grouped into low- $(<4)$, moderate- (4-6), and high-risk categories $(\geq 7)$ (Fig. 6), with 6-month low-, moderate-, and high-risk group incidence percentages being $1 \%, 4 \%$, and $17 \%$ among XPRES enrollees and $1 \%$, $5 \%$, and $30 \%$ among TBFT enrollees. Similarly, for the CD4-dependent clinical score, risk scores were grouped into low- $(<5)$, moderate- $(5-8)$, and highrisk categories $(\geq 9)$ (Fig. 6), with 6-month low-, moderate-, and high-risk group mortality percentages being $0 \%, 4 \%$, and $18 \%$ for XPRES enrollees and $3 \%$, $5 \%$, and $16 \%$ for TBFT enrollees. Figure 7 shows K-M failure curves of mortality over the first 6 months of ART according to the low-, moderate-, and high-risk groups, indicating that specific populations of moderately high- and high-risk groups, in high need of care 


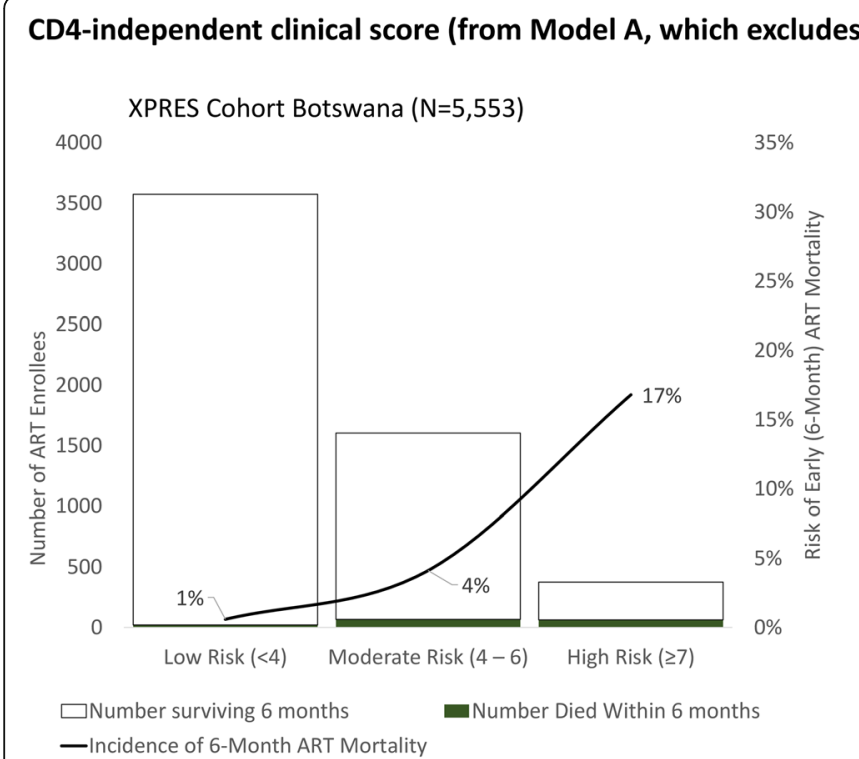

CD4)

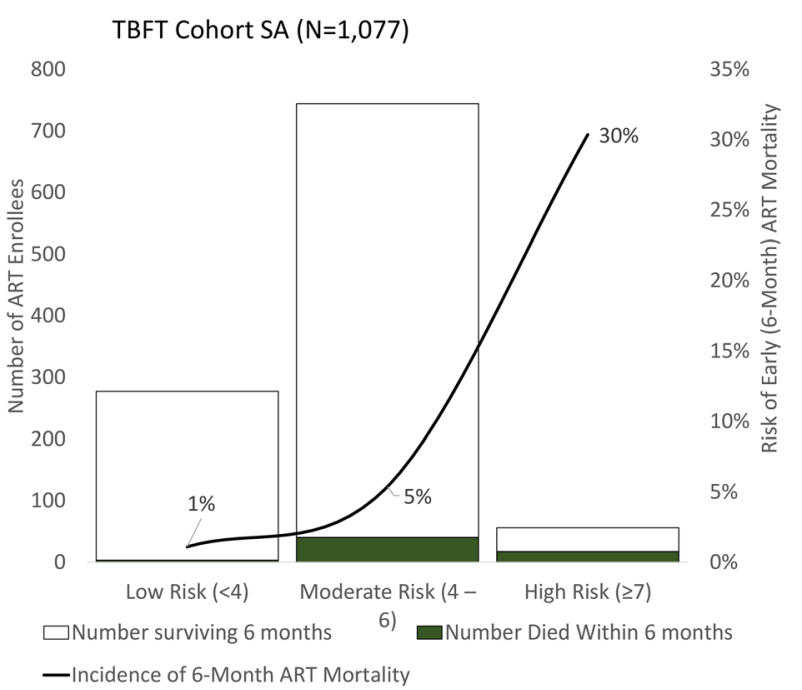

\section{CD4-dependent clinical score (from Model A, which includes CD4)}

XPRES Cohort Botswana $(N=5,553)$ 4000
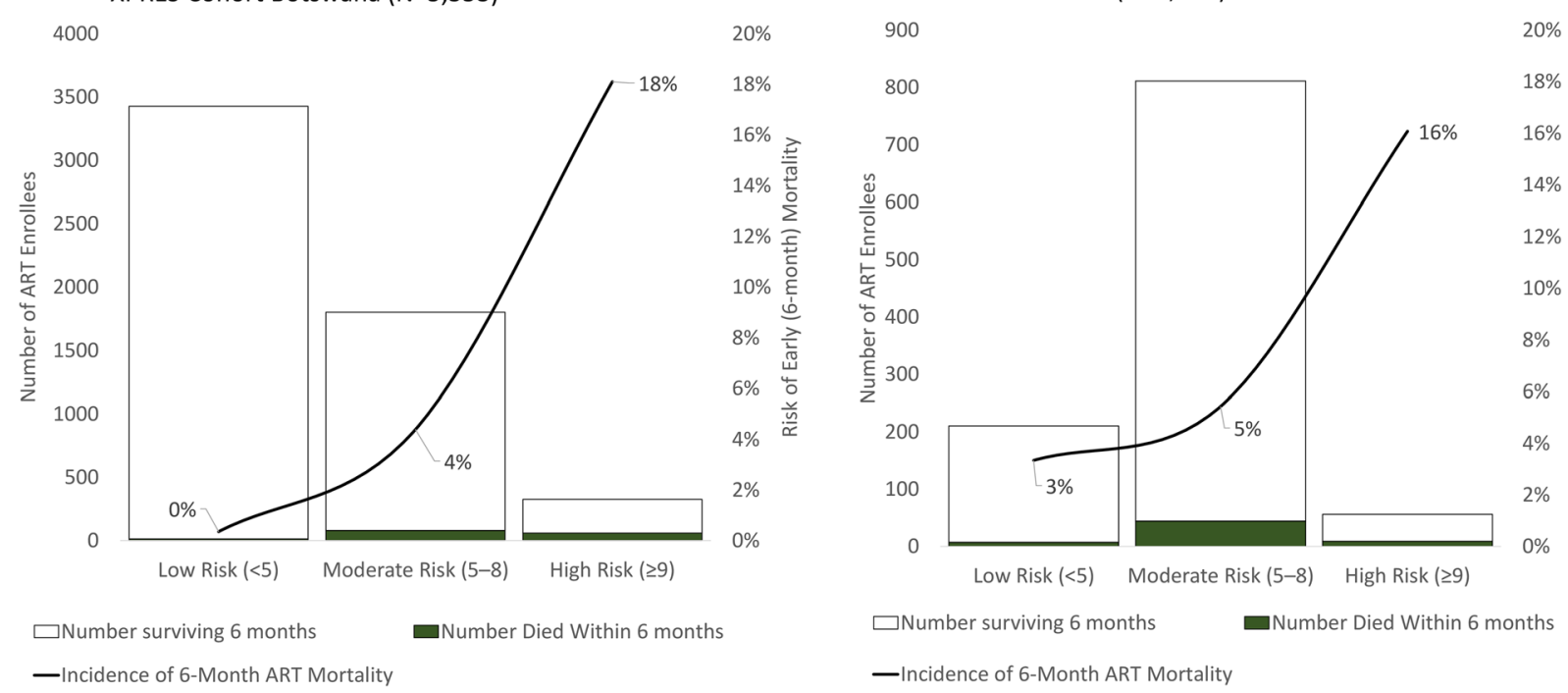

$\square$ Number surviving 6 months
—Incidence of 6-Month ART Mortality

$\square$ Number Died Within 6 months

- Incidence of 6-Month ART Mortality

Fig. 6 Distribution of risk scores and 6-month mortality risk in the XPRES dataset ( $N=5553)$ and external validation TB Fast Track Dataset $(N=1077)$ for models A (excluding CD4) and B (including CD4)

intensification, were differentiated by the respective clinical scores.

\section{Discussion}

To our knowledge, these are the first externally validated clinical scores for ART care intensification generated for SSA. The scores, which have superior screening accuracy characteristics in predicting early mortality risk than WHO-recommended advanced disease eligibility criteria, are not dependent on CD4 testing access, can differentiate mortality risk into three risk groups, could improve access to evidence-based early ART care packages, improve efficiency of advanced disease DSD models, and facilitate improved differentiated care [9].

The CD4-independent clinical score, designed for settings where $\mathrm{CD} 4$ is unavailable at ART intitiation, with a cut-off score of $\geq 4$ was largely as sensitive (86-95\%) in screening in persons at risk of death by 6 months as the current WHO advanced disease eligibility criteria (83$100 \%)$ and nearly twice as sensitive as WHO eligibility criteria that would rely on WHO stage alone (48\%). Compared with the CD4-based WHO advanced disease 


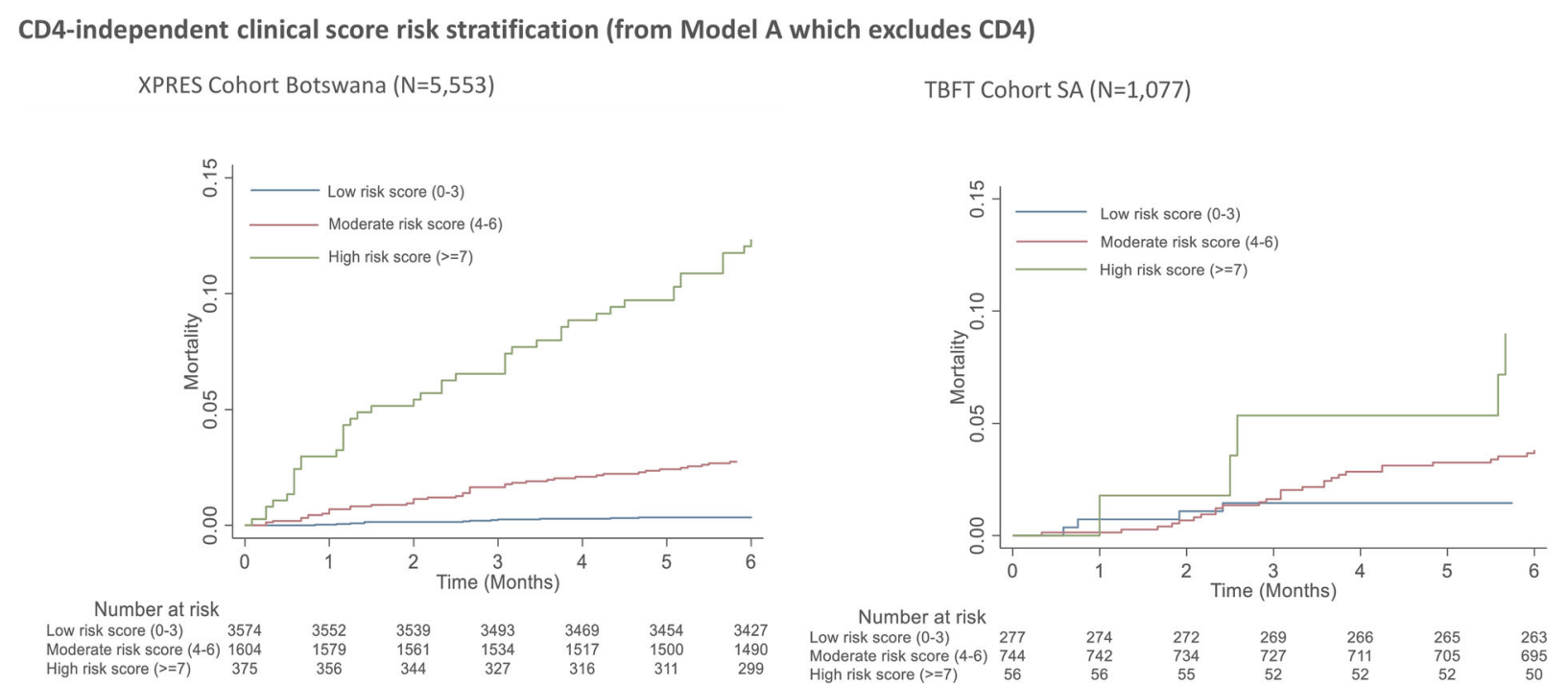

CD4-dependent clinical score risk stratification (from Model B which includes CD4)

XPRES Cohort Botswana $(\mathrm{N}=5,553)$

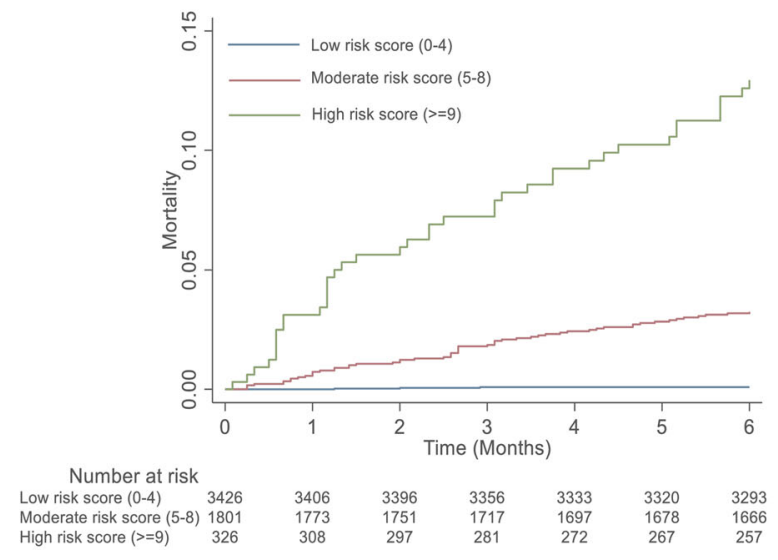

Number at risk $\begin{array}{ll}\text { Low risk score (0-4) } & 342 \\ \text { Moderate risk score (5-8) } & 1801\end{array}$ $\begin{array}{ll}\text { Moderate risk score (5-8) } & 180 \\ \text { High risk score }(>=9) & \end{array}$

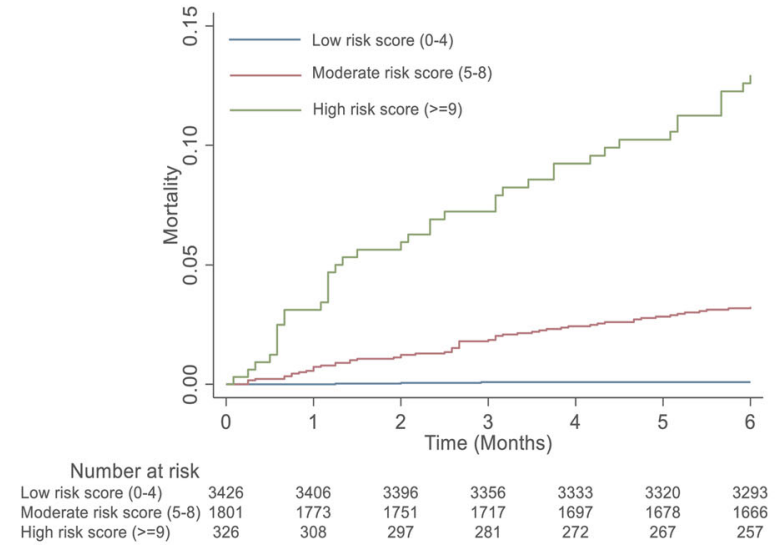

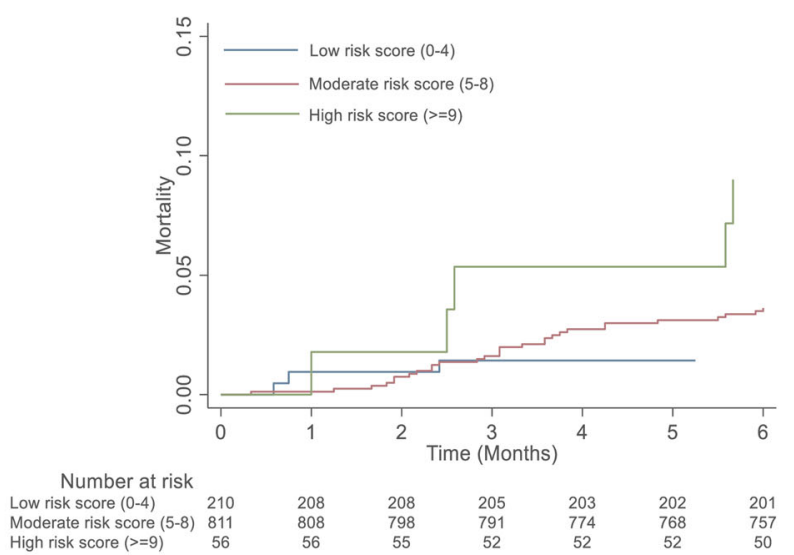

Fig. 7 Survival curves stratified by risk scores in the XPRES dataset $(N=5553)$ and external validation TB Fast Track Dataset $(N=1077)$ for models A (excluding CD4) and B (including CD4)

eligibility criteria, the CD4-independent clinical score had higher specificity and would screen $8-26 \%$ fewer ART enrollees into intensified care pathways, suggesting the screening tool could also increase efficiency of investments in DSD models for advanced disease. Therefore, in the many settings in SSA that lack access to rapid CD4 testing, the CD4-independent clinical score should be considered for scale-up to facilitate early ART care intensification, with the potential for reductions in early ART mortality [11]. In addition, in those settings where CD4 is available, using the CD4-dependent clinical score with a cut-off score of $\geq 5$ could have similar or increased sensitivity and superior specificity compared with WHO advanced disease eligibility criteria, with the potential to both reduce early ART mortality and improve efficiency of DSD algorithms.

In contrast to current $\mathrm{WHO}$ guidelines, which recommend only the use of CD4 count and WHO HIV disease staging to identify patients at high risk for morbidity and mortality, our composite risk score provides both more comprehensive and specific information on the magnitude of risk for each patient by integrating additional objective variables into the assessment [9]. The additional variables included in our score are both clinical and demographic. The clinical variables of WHO TB symptom screen, temperature, and anemia severity are known to be associated with serious comorbidities that significantly increase early 
mortality risk, while the demographic variable in the scores (the gender variable of male, female nonpregnant, and female pregnant) captures important generalizable differences in early mortality risk in SSA, which are due to both psychosocial and biological factors $[28,29]$. Our risk scores are careful to be simple ( 5 or 6 variables assessed), use objective covariates rather than variables that are more open to interpretation, and use variables that should be available, or could easily be made available, at the POC in LMIC. Our score could be relatively easily included in paper medical records relevant for the first HIV clinic or ART initiation visit and should not require a calculator, unlike clinical scores developed for resource-rich settings that require either electronic medical record or website access to calculate the score (e.g., the Veterans Aging Cohort Study (VACS) or EuroSIDA scores) [30-32].

The hemoglobin concentration variable in our scores is more available in LMIC than POC CD4 testing, although scale-up of CD4 testing is needed and ongoing. Notably, WHO has long designated hemoglobin testing one of four essential laboratory services in SSA [33], and hemoglobin tests are the most commonly performed laboratory test globally [34, 35]. For example, in Malawi, one of the most resource-constrained countries in the world which is ranked 172 out of 189 countries on the human development index, hemoglobin testing through point-of-care HemoCue ${ }^{\circ}$ [34] or the WHO Hemoglobin Color Scale is relatively widely available [35]. In the 2014 Malawi national health facility survey to assess access to diagnostic tests, $82 \%$ of hospitals had access to hemoglobin testing, with access only superseded by malaria diagnostic testing (95\%) and HIV diagnostic testing (95\%), whereas CD4 testing was only available in $43 \%$ of hospitals [36]. Across all health facility types (hospitals, health centers, clinics, and health posts), hemoglobin testing was three times more widely available than CD4 testing [36], although there is a need for scale-up of both tests. In addition to being currently more widely accessible in SSA than CD4 testing, POC hemoglobin testing is currently easier to scale up than CD4 testing. Available POC hemoglobin measurement devices tend to be durable, easy to use, and not reliant on electricity supply, and require minimal training and supervision [34] while also providing good accuracy in LMIC [37, 38]. To date, these POC hemoglobin devices have been less expensive than currently available POC CD4 systems and are useful for non-HIVrelated care (e.g., <\$100/POC hemoglobin measurement device and $\$ 0.12-0.75 /$ test [34] vs. about $\$ 7430$ / POC CD4 device and about \$8.70/test [39]). Both CD4 testing and hemoglobin testing are important at the point of care, and less expensive POC CD4 lateral flow assays and transcutaneous spectrophotometry solutions for hemoglobin level measurement may become available in the future [40-42].

Additional advantages of developing clinical scores with a variety of cut-offs are that it allows program managers to choose cut-offs with associated screening accuracy characteristics, allowing program managers to choose cut-offs based on funding availability, by trading sensitivity for improved specificity [9].

Another potential advantage of the combined clinical score over the WHO advanced disease criteria is the ability to differentiate three risk groups (low, moderate, and high), with the highest risk group having 6-month mortality rates of $16-30 \%$ versus $0-3 \%$ in the low and $4-5 \%$ in the moderate risk groups. While all patients with moderate or high scores might benefit from standardized outpatient intensified early ART care, patients in the highest risk group might be candidates for additional interventions to help navigate the relatively complex time of early ART. During this time, clinicians need to rapidly search for, diagnose, or rule out comorbidities, and both choose and time appropriate therapies, all within the context of ART-driven immune reconstitution $[43,44]$. Our clinical score could be used to inform a clinical trial of such interventions.

Moderate to severe anemia was a stronger predictor than CD4 count and overall was the strongest predictor of early ART mortality in our cohort, similar to other studies in SSA $[21,45,46]$. Anemia is the most common hematological complication of HIV disease among PLHIV [47] and develops through several mechanisms including direct HIV infection of hematopoietic progenitor cells, dysregulated erythropoiesis through indirect effects of proinflammatory cytokines, and through anemia of chronic disorders (ACD), which is thought to be the most common pathway [48]. ACD is driven by hepatic expression of hepcidin, an acute phase reactant that causes iron to be diverted from the circulation and sequestered within cells of the reticuloendothelial system through downregulation of ferroportin channels [49]. TB also drives ACD through this hepcidin-ferroportin interaction $[49,50]$. In turn, sequestration of iron inside macrophages and $\mathrm{T}$ cells might support both intracellular mycobacterial growth [46, 49] and HIV viral replication [51], showing the potential for rapid worsening of HIV, TB, and severe hepcidin-driven anemia. Therefore, although ART is the most important treatment of HIV-associated anemia, early treatment of any associated co-infections is crucial [46]. In a separate analysis, we show that moderate to severe anemia was also predictive of active TB infection in the XPRES cohort, similar to other analyses [46]. Given the strong association between moderate to severe anemia, early mortality, and active TB, 
which is the most common cause of early mortality in SSA [52], the scores associated with observed moderate-severe anemia in this analysis (2-4 points) appropriately bring the total clinical score very close to the threshold for ART care intensification. Per current WHO guidelines, care intensification should include further investigations for TB, especially disseminated $\mathrm{TB}$, through the use of the urine TB-LAM assay and Xpert MTB/RIF [46, 50, 53, 54].

Another notable finding is that measured temperature at $>37.5^{\circ} \mathrm{C}$ at $\mathrm{ART}$ initiation was strongly predictive of early ART mortality, independent of the WHO TB symptom screen for fever or night sweats, which was also predictive of mortality. This indicates the importance of objective measures of fever in addition to patient history [23]. In addition, our analysis shows that in those settings where measured temperature measurement is not available, measured heart rate $(>120$ versus $\leq 120$ / $\mathrm{min}$ ) is a suitable replacement variable. Notably, some of the key inflammatory cytokines that drive hepcidin release and fever are the same (e.g., interleukin (IL)-6, tumor necrosis factor which stimulates IL-6 release, interferons, and microbial-derived Toll-like receptors) and are important for both pathways $[49,55]$. Disseminated undiagnosed TB or TB diagnosed late is the most common infectious cause of death among PLHIV in subSaharan Africa, accounting for about $40 \%$ of deaths [52]. However, a recent autopsy study of causes of death among new HIV clinic enrollees in SA found that 59\% of decedents had evidence of two or more concurrent infections [56]. Most bacterial infections were due to common pathogens, such as Klebsiella spp., Salmonella spp., Haemophilus influenzae, and Staphylococcus aureus, while cryptococcal infection was found in 13\% [56]. Targeting an antimicrobial package of interventions to patients who screen positive for our proposed clinical scores, such as the package of interventions recommended by WHO or trialed in the REALITY trial (continuous trimethoprim-sulfamethoxazole, $\geq 12$ weeks of isoniazid-pyridoxine (once active TB is ruled out), 12 weeks of fluconazole, 5 days of azithromycin, and a single dose of albendazole), could significantly reduce mortality for patients who screen positive [11].

The prognostic importance of male gender in predicting mortality was correlated with older age and smoking history in our model, and we chose to include the single gender variable rather than two additional variables (age $\geq 55$ and smoking) in the CD4-dependent clinical score to make the most parsimonious clinical score and because male gender is a more generalizable predictor of poor outcomes in SSA $[29,57,58]$. In addition, similar to many ART programs in SSA [20, 59], pregnant women in XPRES, who were (1) more likely to be diagnosed at an earlier disease stage through routine testing at antenatal care and (2) able to initiate ART immediately once diagnosed unlike non-pregnant women diagnosed with HIV at the time [15], had lower mortality than non-pregnant women starting ART in bivariate analysis $[20,59]$. However, if ART programs in SSA are able in the future to achieve earlier testing and ART initiation for male and non-pregnant female PLHIV, it is likely gender and pregnancy status could become less important predictors, while predictors like smoking and older age will become more important [57]. Although smoking is not part of the clinical score, this article provides additional evidence for the need for tobacco smoking reduction programs for PLHIV, separate or included in early ART care intensification algorithms, to minimize not only the risk of ischemic cardiovascular diseases but also the risk of malignancies and bacterial infections, including TB [60].

Strengths of this study include the use of data from prospective cohorts nested within clinical trials, meaning there was minimal missing covariate data and strong ascertainment of the primary outcome of interest (6month ART mortality) (e.g., only one patient was LTFU from the XPRES cohort and was excluded from this analysis [16]). Additional strengths include the relatively high screening accuracy in both the XPRES and TBFT cohorts, from two geographically separate cohorts, with very different cohort characteristics (e.g., XPRES enrollees represent general outpatient ART enrollees while TBFT enrollees had homogenously low CD4 counts $(<$ $150 / \mu \mathrm{L})$ ). Notably, discrimination, as measured by the AUROC of the clinical scores, was lower in the TBFT than in the XPRES cohort, but at the chosen clinical score cut-offs, the clinical score still provided similar sensitivity and superior specificity in predicting early ART mortality compared with the WHO advanced disease eligibility criteria. The lower discriminatory capacity of the clinical scores in the TBFT cohort is not surprising given the TBFT cohort reflects a relatively homogenous ART population with advanced HIV disease. Notably, while in the XPRES cohort 6\% of ART enrollees were newly diagnosed and treated for TB, in the TBFT cohort $62 \%$ were treated for TB through a risk-based TB-treatment algorithm [14], suggesting that the risk score is likely to be generalizable across a wide range of new ART enrollee cohorts. However, additional validation exercises are needed and planned to further assess generalizability.

Limitations include that the risk score has not yet been validated in a cohort enrolled under HIV test-and-treat guidelines, something which is planned in the near future. Other limitations include the fact that while the gender and pregnancy variable is relevant in SSA and many resource-limited settings, it is not generalizable to cohorts in resource-rich settings like the USA and 
Europe, where males often have better outcomes than female ART enrollees. Although the specificity of the clinical scores is superior to the WHO advanced disease eligibility criteria, a substantial percentage of ART enrollees (36-38\% in the XPRES cohort) would be screened into receiving an advanced disease care package, which would require a monitoring system to assess implementation fidelity. In addition, these screening tools were validated in clinical trial cohorts that received relatively intensive TB screening and treatment services, and therefore, those that died did so despite access these services. Finally, although the clinical score is highly sensitive in screening in almost all patients with low CD4 count and advanced WHO disease stage at risk of death into intensification of care pathways, and has superior or similar sensitivity to current WHO advanced disease screening criteria, it is possible for some patients with a very low CD4 count and advanced WHO stage to have a clinical score that falls below the specified cut-off, and clinical discretion to screen these rare patients missed by the screening tool into intensification of care pathways is warranted.

\section{Conclusions}

In conclusion, where $\mathrm{CD} 4$ testing is not available in similar LMIC, especially in SSA, the CD4-independent risk score should be strongly considered for scale-up to facilitate early ART care intensification, with the potential for significant reductions in early ART mortality if targetted individuals are provided with evidence-based care packages [11]. For clinics where CD4 count is available, the use of the CD4-dependent clinical score could improve both sensitivity and specificity over WHO advanced disease eligibility criteria, with the potential to reduce early ART mortality and improve efficiency of DSD algorithms. Finally, further research to understand best management of ART enrollees enrolled in the highest risk categories is warranted to further explore mortality reduction interventions. Together, these actions could help drive progress to AIDS 2030 goals of zero AIDS deaths in the region of the world with the highest HIV/AIDS-associated mortality.

\section{Supplementary information}

Supplementary information accompanies this paper at https://doi.org/10. 1186/s12916-020-01775-8.

Additional file 1. Table showing HIV care clinical follow-up of clients in the Botswana XPRES cohort (2010-2015).

Additional file 2. Text showing XPRES enrollment and follow-up procedures.

Additional file 3. Tripod checklist for prediction model development and validation.

Additional file 4. Table showing Hosmer-Lemeshow tests for calibration of final models A (CD4 excluded) and B (CD4 included).
Additional file 5. Figure showing association between 6-month ART mortality risk and (a) temperature and (b) heart rate, at ART initiation.

Additional file $\mathbf{6}$ Table showing multivariable model and clinical score generation from the derivation dataset with heart rate replacing the measured temperature variable $(N=2838)$.

Additional file 7. Tables showing performance of clinical score in derivation and validation datasets for Models A (excluding CD4) and B (including CD4).

Additional file 8. Figure showing alternate clinical score screening accuracy with the temperature variable replaced by heart rate.

Additional file 9. Figure showing area under the receiver operating characteristic curve for clinical score performance in combined XPRES dataset $(\mathrm{N}=5553)$ and external validation TB Fast Track Dataset $(\mathrm{N}=$ 1077) for Models A (excluding CD4) and B (including CD4).

\section{Acknowledgements}

The authors would like to thank all study participants, participating health facilities, and project team members for their contributions to improving TB and HIV care in Botswana. We also thank Dr. Tom Spira for his contributions over many years as a mentor, advisor, and subject matter expert and for his review of this manuscript prior to his death on April 2, 2020.

\section{Authors' contributions}

AFA, KF, TA, RB, AD, SP, HA, JCS, TVE, and AG were involved in the study conception and the study design. AFA, TVE, RB, TA, AF, and JCS obtained the funding. AFA, TA, AM, RB, AD, SP, CS, UM, HA, GR, PP, JCS, and AF implemented the study. AFA and KF were the study statisticians. AFA, KF, TA, $\mathrm{SP}, \mathrm{CS}$, and AF were involved in data management. AFA, KF, and ADG planned the analysis. AFA did the analysis. All authors were involved in interpreting the data. AFA wrote the first draft. All authors read and approved the final manuscript.

\section{Funding}

This research has been supported by the President's Emergency Plan for AIDS Relief (PEPFAR) through the US Centers for Disease Control and Prevention (CDC). The funder had no role in the study design, data collection and analysis, decision to publish, or preparation of the manuscript. Disclaimer: The findings and conclusions in this report are those of the authors and do not necessarily represent the official position of the CDC.

\section{Availability of data and materials}

The datasets generated and/or analyzed during the current study are not publicly available due to an IRB decision which was made in the interest of ensuring patient confidentiality but are available from the corresponding author on reasonable request. Per IRB guidance, the datasets will be anonymized before sharing.

\section{Ethics approval and consent to participate}

Ethical approval for each of the source studies was obtained from the relevant ethics committees in the country of data collection and from the trial sponsors. All participants provided informed written consent, or where the enrollee could not read or write, witnessed verbal informed consent. Ethical approvals for XPRES were obtained from the US Centers for Disease Control and Prevention (CDC) Institutional Review Board (IRB) C, the Health Research and Development Division of the Health Research and Development Committee (HRDC) in Botswana, and the University of Pennsylvania IRB No.4. All consent procedures were approved by the ethical review committees. Written informed consent was obtained from all prospective XPRES enrollees. XPRES is registered at ClinicalTrials.gov (trial registration no. NCT02538952). Oversight of study initiation and quarterly review of implementation was conducted by the Office of the Associate Director of Science at CDC Atlanta. TBFT was approved by the research ethics committees of the University of the Witwatersrand, the London School of Hygiene \& Tropical Medicine, and the South African Medicines Control Council. All participants provided written or witnessed verbal informed consent. This trial was registered with the ISRCTN registry, ISRC TN35344604, and the South African National Clinical Trials Register, DOH-270812-3902. 


\section{Consent for publication}

Not applicable.

\section{Competing interests}

The authors declare that they have no competing interests.

\section{Author details}

'Division of Global HIV \& TB, United States Centers for Disease Control and Prevention (CDC), Nico House, City Centre, P.O. Box 30016, Lilongwe 3, Malawi. ${ }^{2}$ TB Centre, London Sch. of Hygiene \& Tropical Med, London, UK. ${ }^{3}$ School of Public Health, University of the Witwatersrand, Johannesburg, South Africa. ${ }^{4}$ Division of TB Elimination, Centers for Disease Control and Prevention, Gaborone, Botswana. ${ }^{5}$ Division of Global HIV \& TB, Centers for Disease Control and Prevention, Atlanta, GA, USA. ${ }^{6}$ Bill and Melinda Gates Foundation, Seattle, WA, USA. ${ }^{7}$ Aurum Institute, Johannesburg, South Africa. ${ }^{8}$ Ministry of Health and Wellness, Gaborone, Botswana. ${ }^{9}$ Yale University School of Medicine, New Haven, CT, USA. ${ }^{10}$ Center for Global Health Practice and Impact, Georgetown University Medical Center, Washington D.C, USA.

${ }^{11}$ Africa Health Research Institute, School of Nursing and Public Heath,

University of KwaZulu-Natal, Durban, South Africa.

\section{Received: 6 May 2020 Accepted: 2 September 2020}

\section{Published online: 09 November 2020}

\section{References}

1. UNAIDS. AIDSinfo. Available at: http://aidsinfo.unaids.org/. Accessed 5 June 2020.

2. Tanser F, Bärnighausen T, Grapsa E, Zaidi J, Newell ML. High coverage of ART associated with decline in risk of HIV acquisition in rural KwaZulu-Natal, South Africa. Science. 2013;339(6122):966-71.

3. Vandormael A, Akullian A, Siedner M, de Oliveira T, Barnighausen T, Tanser F. Declines in HIV incidence among men and women in a South African population-based cohort. Nat Commun. 2019;10(1):5482.

4. Stover J, Bollinger L, Izazola JA, Loures L, DeLay P, Ghys PD, et al. What is required to end the AIDS epidemic as a public health threat by 2030? The cost and impact of the fast-track approach. PLoS One. 2016;11(5):e0154893.

5. Gupta A, Nadkarni G, Yang WT, Chandrasekhar A, Gupte N, Bisson GP, et al, Early mortality in adults initiating antiretroviral therapy (ART) in low- and middle-income countries (LMIC): a systematic review and meta-analysis. PLoS One. 2011;6(12):e28691.

6. Haas AD, Zaniewski E, Anderegg N, Ford N, Fox MP, Vinikoor M, et al. Retention and mortality on antiretroviral therapy in sub-Saharan Africa: collaborative analyses of HIV treatment programmes. J Int AIDS Soc. 2018. 21(2):e25084.

7. Auld AF, Shiraishi RW, Oboho I, Ross C, Bateganya M, Pelletier V, et al. Trends in prevalence of advanced HIV disease at antiretroviral therapy enrollment - 10 countries, 2004-2015. MMWR Morb Mortal Wkly Rep. 2017; 66(21):558-63.

8. WHO. Guidelines for managing advanced HIV disease and rapid initiation of antiretroviral therapy. Available at: https://www.ncbi.n/m.nih.gov/pubmed/2 9341560. Accessed 4 Jan 2020

9. McNairy ML, Abrams EJ, Rabkin M, El-Sadr WM. Clinical decision tools are needed to identify HIV-positive patients at high risk for poor outcomes after initiation of antiretroviral therapy. PLoS Med. 2017;14(4):e1002278.

10. WHO. HIV Treatment and Care, What's new in service delivery fact sheet Available at: http://apps.who.int/iris/bitstream/10665/204461/1/WHO_HIV_2 015.46_eng.pdf?ua=1. Accessed 4 Jan 2020.

11. Hakim J, Musiime V, Szubert AJ, Mallewa J, Siika A, Agutu C, et al. Enhanced prophylaxis plus antiretroviral therapy for advanced HIV infection in Africa. N Engl J Med. 2017;377(3):233-45

12. McNairy ML, Jannat-Khah D, Pape JW, Marcelin A, Joseph P, Mathon JE, et al. Predicting death and lost to follow-up among adults initiating antiretroviral therapy in resource-limited settings: derivation and external validation of a risk score in Haiti. PLoS One. 2018;13(8):e0201945.

13. Auld AF, Agizew T, Pals S, Finlay A, Ndwapi N, Boyd R, et al. Implementation of a pragmatic, stepped-wedge cluster randomized trial to evaluate impact of Botswana's Xpert MTB/RIF diagnostic algorithm on TB diagnostic sensitivity and early antiretroviral therapy mortality. BMC Infect Dis. 2016; 16(1):606

14. Grant AD, Charalambous S, Tlali M, Karat AS, Dorman SE, Hoffmann CJ, et al. Algorithm-guided empirical tuberculosis treatment for people with advanced HIV (TB Fast Track): an open-label, cluster-randomised trial. Lancet HIV. 2020;7(1):e27-e37.

15. Dryden-Peterson S, Lockman S, Zash R, Lei Q, Chen JY, Souda S, et al. Initial programmatic implementation of WHO option B in Botswana associated with increased projected MTCT. J Acquir Immune Defic Syndr. 2015;68(3): 245-9.

16. Auld AF, Agizew T, Mathoma A, Boyd R, Date A, Pals SL, et al. Effect of tuberculosis screening and retention interventions on early antiretroviral therapy mortality in Botswana: a stepped-wedge cluster randomized trial. BMC Med. 2020;18(1):19.

17. Altman DG, Vergouwe $Y$, Royston $P$, Moons KG. Prognosis and prognostic research: validating a prognostic model. BMJ. 2009;338:b605.

18. Brinkhof MW, Pujades-Rodriguez M, Egger M. Mortality of patients lost to follow-up in antiretroviral treatment programmes in resource-limited settings: systematic review and meta-analysis. PLoS One. 2009:4(6): e5790.

19. Royston P, Moons KG, Altman DG, Vergouwe Y. Prognosis and prognostic research: developing a prognostic model. BMJ. 2009;338:b604.

20. Auld AF, Shiraishi RW, Couto A, Mbofana F, Colborn K, Alfredo C, et al. A decade of antiretroviral therapy scale-up in Mozambique: evaluation of outcome trends and new models of service delivery among more than 300,000 patients enrolled during 2004-2013. J Acquir Immune Defic Syndr 2016;73(2):e11-22.

21. May M, Boulle A, Phiri S, Messou E, Myer L, Wood R, et al. Prognosis of patients with HIV-1 infection starting antiretroviral therapy in sub-Saharan Africa: a collaborative analysis of scale-up programmes. Lancet. 2010; 376(9739):449-57

22. Worodria W, Chang E, Andama A, Sanyu I, Byanyima P, Musisi E, et al. Predictors of mortality among hospitalized patients with lower respiratory tract infections in a high HIV burden setting. J Acquir Immune Defic Syndr. 2018;79(5):624-30

23. Holmes CB, Sikazwe I, Sikombe K, Eshun-Wilson I, Czaicki N, Beres LK, et al. Estimated mortality on HIV treatment among active patients and patients lost to follow-up in 4 provinces of Zambia: findings from a multistage sampling-based survey. PLoS Med. 2018;15(1):e1002489.

24. Moons KG, Altman DG, Vergouwe Y, Royston P. Prognosis and prognostic research: application and impact of prognostic models in clinical practice. BMJ. 2009:338:b606.

25. WHO. Haemoglobin concentrations for the diagnosis of anaemia and assessment of severity (2011). Available at: https://www.who.int/vmnis/ indicators/haemoglobin/en/. Accessed 4 Jan 2020.

26. Del Bene VE. Clinical methods: the history, physical, and laboratory examinations. 3rd edition. Chapter 218Temperature. Available at: https:// www.ncbi.nlm.nih.gov/books/NBK331/. Accessed 4 Jan 2020.

27. Koss CA, Jarlsberg LG, den Boon S, Cattamanchi A, Davis JL, Worodria W, et al. A clinical predictor score for 30-day mortality among HIV-infected adults hospitalized with pneumonia in Uganda. PLoS One. 2015;10(5):e0126591.

28. McNairy ML, Howard AA, El-Sadr WM. Antiretroviral therapy for prevention of HIV and tuberculosis: a promising intervention but not a panacea. $J$ Acquir Immune Defic Syndr. 2013;63(Suppl 2):S200-7.

29. Auld AF, Shiraishi RW, Mbofana F, Couto A, Fetogang EB, El-Halabi S, et al. Lower levels of antiretroviral therapy enrollment among men with HIV compared with women - 12 countries, 2002-2013. MMWR Morb Mortal Wkly Rep. 2015;64(46):1281-6

30. Tate JP, Sterne JAC, Justice AC, Veterans Aging Cohort S, the Antiretroviral Therapy Cohort C. Albumin, white blood cell count, and body mass index improve discrimination of mortality in HIV-positive individuals. AIDS. 2019; 33(5):903-912.

31. Mocroft A, Ledergerber B, Zilmer K, Kirk O, Hirschel B, Viard JP, et al. Shortterm clinical disease progression in HIV-1-positive patients taking combination antiretroviral therapy: the EuroSIDA risk-score. AIDS. 2007; 21(14):1867-75.

32. Justice AC, Modur SP, Tate JP, Althoff KN, Jacobson LP, Gebo KA, et al. Predictive accuracy of the Veterans Aging Cohort Study index for mortality with HIV infection: a North American cross cohort analysis. J Acquir Immune Defic Syndr. 2013;62(2):149-63.

33. Petti CA, Polage CR, Quinn TC, Ronald AR, Sande MA. Laboratory medicine in Africa: a barrier to effective health care. Clin Infect Dis. 2006:42(3):377-82.

34. Medina Lara A, Mundy C, Kandulu J, Chisuwo L, Bates I. Evaluation and costs of different haemoglobin methods for use in district hospitals in Malawi. J Clin Pathol. 2005;58(1):56-60. 
35. Marn H, Critchley JA. Accuracy of the WHO Haemoglobin Colour Scale for the diagnosis of anaemia in primary health care settings in low-income countries: a systematic review and meta-analysis. Lancet Glob Health. 2016; 4(4):e251-65.

36. Malawi Ministry of Health. Facility-level infrastructure, resources, management, and support. Available at: https://dhsprogram.com/pubs/pdf/ SPA20/SPA20\%5BOct-7-2015\%5D.pdf. Accessed 1 Aug 2020.

37. Nkrumah B, Nguah SB, Sarpong N, Dekker D, Idriss A, May J, et al. Hemoglobin estimation by the HemoCue(R) portable hemoglobin photometer in a resource poor setting. BMC Clin Pathol. 2011:11:5.

38. Sanchis-Gomar F, Cortell-Ballester J, Pareja-Galeano H, Banfi G, Lippi G. Hemoglobin point-of-care testing: the HemoCue system. J Lab Autom. 2013;18(3):198-205.

39. Larson B, Schnippel K, Ndibongo B, Long L, Fox MP, Rosen S. How to estimate the cost of point-of-care CD4 testing in program settings: an example using the Alere Pima Analyzer in South Africa. PLoS One. 2012;7(4):e35444.

40. Gayat E, Aulagnier J, Matthieu E, Boisson M, Fischler M. Non-invasive measurement of hemoglobin: assessment of two different point-of-care technologies. PLoS One. 2012;7(1):e30065.

41. Crowley C, Montenegro-Bethancourt G, Solomons NW, Schumann K. Validity and correspondence of non-invasively determined hemoglobin concentrations by two trans-cutaneous digital measuring devices. Asia Pac J Clin Nutr. 2012;21(2):191-200.

42. PATH. Noninvasive technology for anemia detection (2013). Seattle. PATH. Available at: http://www.path.org/publications/files/TS_update_anemia.pdf. Accessed 4 Jan 2020.

43. Mfinanga SG, Kirenga BJ, Chanda DM, Mutayoba B, Mthiyane T, Yimer G, et al. Early versus delayed initiation of highly active antiretroviral therapy for HIV-positive adults with newly diagnosed pulmonary tuberculosis (TB-HAAR T): a prospective, international, randomised, placebo-controlled trial. Lancet Infect Dis. 2014;14(7):563-71

44. Boulware DR, Meya DB, Muzoora C, Rolfes MA, Huppler Hullsiek K, Musubire A, et al. Timing of antiretroviral therapy after diagnosis of cryptococcal meningitis. N Engl J Med. 2014;370(26):2487-98.

45. Harris RJ, Sterne JA, Abgrall S, Dabis F, Reiss P, Saag M, et al. Prognostic importance of anaemia in HIV type-1-infected patients starting antiretroviral therapy: collaborative analysis of prospective cohort studies. Antivir Ther. 2008;13(8):959-67.

46. Kerkhoff AD, Wood R, Cobelens FG, Gupta-Wright A, Bekker LG, Lawn SD. The predictive value of current haemoglobin levels for incident tuberculosis and/or mortality during long-term antiretroviral therapy in South Africa: a cohort study. BMC Med. 2015;13:70.

47. Belperio PS, Rhew DC. Prevalence and outcomes of anemia in individuals with human immunodeficiency virus: a systematic review of the literature. Am J Med. 2004;116(Suppl 7A):27S-43S.

48. Gibellini D, Clo A, Morini S, Miserocchi A, Ponti C, Re MC. Effects of human immunodeficiency virus on the erythrocyte and megakaryocyte lineages. World J Virol. 2013;2(2):91-101.

49. Drakesmith $\mathrm{H}$, Prentice AM. Hepcidin and the iron-infection axis. Science 2012;338(6108):768-72.

50. Kerkhoff AD, Meintjes G, Burton R, Vogt M, Wood R, Lawn SD. Relationship between blood concentrations of hepcidin and anemia severity, mycobacterial burden, and mortality among patients with HIV-associated tuberculosis. J Infect Dis. 2016;213(1):61-70.

51. Xu M, Kashanchi F, Foster A, Rotimi J, Turner W, Gordeuk VR, et al. Hepcidin induces HIV-1 transcription inhibited by ferroportin. Retrovirology. 2010;7:104.

52. Gupta RK, Lucas SB, Fielding KL, Lawn SD. Prevalence of tuberculosis in post-mortem studies of HIV-infected adults and children in resource-limited settings: a systematic review and meta-analysis. AIDS. 2015;29(15):19872002.

53. Kerkhoff AD, Wood R, Lawn SD. Optimum time to start antiretroviral therapy in patients with HIV-associated tuberculosis: before or after tuberculosis diagnosis? AIDS. 2011;25(7):1003-6.

54. WHO. Lateral flow urine lipoarabinomannan assay (LF-LAM) for the diagnosis of active tuberculosis in people living with HIV. Available at: https://www.who.int/tb/publications/2019/LAMPolicyUpdate2019/en/. Accessed 4 Jan 2020.

55. Netea MG, Kullberg BJ, Van der Meer JW. Circulating cytokines as mediators of fever. Clin Infect Dis. 2000;31(Suppl 5):S178-84.

56. Karat AS, Omar T, von Gottberg A, Tlali M, Chihota VN, Churchyard GJ, et al. Autopsy prevalence of tuberculosis and other potentially treatable infections among adults with advanced HIV enrolled in out-patient care in South Africa. PLoS One. 2016;11(11):e0166158.

57. Gupta-Wright A, Corbett EL, Wilson D, van Oosterhout JJ, Dheda K, Huerga $\mathrm{H}$, et al. Risk score for predicting mortality including urine lipoarabinomannan detection in hospital inpatients with HIV-associated tuberculosis in sub-Saharan Africa: derivation and external validation cohort study. PLoS Med. 2019;16(4):e1002776

58. Centers for Disease C, Prevention. Differences between HIV-infected men and women in antiretroviral therapy outcomes - six African countries, 20042012. MMWR Morb Mortal Wkly Rep. 2013;62(47):946-52.

59. Pati R, Lahuerta M, Elul B, Okamura M, Alvim MF, Schackman B, et al. Factors associated with loss to clinic among HIV patients not yet known to be eligible for antiretroviral therapy (ART) in Mozambique. J Int AIDS Soc. 2013; 16:18490.

60. Benard A, Tessier JF, Rambeloarisoa J, Bonnet F, Fossoux H, Neau D, et al. HIV infection and tobacco smoking behaviour: prospects for prevention? ANRS CO3 Aquitaine Cohort, 2002. Int J Tuberc Lung Dis. 2006;10(4):378-83.

\section{Publisher's Note}

Springer Nature remains neutral with regard to jurisdictional claims in published maps and institutional affiliations.
Ready to submit your research? Choose BMC and benefit from:

- fast, convenient online submission

- thorough peer review by experienced researchers in your field

- rapid publication on acceptance

- support for research data, including large and complex data types

- gold Open Access which fosters wider collaboration and increased citations

- maximum visibility for your research: over $100 \mathrm{M}$ website views per year

At BMC, research is always in progress.

Learn more biomedcentral.com/submissions 